\title{
Evaluation of ECMWF-IFS (version 41R1) operational model forecasts of aerosol transport by using ceilometer network measurements
}

\author{
Ka Lok Chan ${ }^{1,2}$, Matthias Wiegner ${ }^{1}$, Harald Flentje ${ }^{3}$, Ina Mattis ${ }^{3}$, Frank Wagner ${ }^{3, a}$, Josef Gasteiger ${ }^{4}$, and \\ Alexander Geiß ${ }^{1}$ \\ ${ }^{1}$ Meteorological Institute, Ludwig-Maximilians-Universität München, Munich, Germany \\ ${ }^{2}$ Remote Sensing Technology Institute, German Aerospace Center (DLR), Oberpfaffenhofen, Germany \\ ${ }^{3}$ Department of Research and Development, Meteorological Observatory Hohenpeißenberg, \\ German Weather Service (DWD), Hohenpeißenberg, Germany \\ ${ }^{4}$ Aerosol Physics and Environmental Physics, University of Vienna, Vienna, Austria \\ anow at: Institute for Meteorology and Climate Research, Karlsruhe Institute of Technology, \\ Eggenstein-Leopoldshafen, Germany
}

Correspondence: Ka Lok Chan (ka.chan@dlr.de)

Received: 13 March 2018 - Discussion started: 2 May 2018

Revised: 13 August 2018 - Accepted: 5 September 2018 - Published: 25 September 2018

\begin{abstract}
In this paper, we present a comparison of model simulations of aerosol profiles with measurements of the ceilometer network operated by the German Weather Service (DWD) over 1 year from September 2015 to $\mathrm{Au}$ gust 2016. The aerosol forecasts are produced by the Copernicus Atmosphere Monitoring Service (CAMS) using the aerosol module developed within the Global and regional Earth-system Monitoring using Satellite and in-situ data (GEMS) and Monitoring Atmospheric Composition and Climate (MACC) projects and coupled into the European Centre for Medium-Range Weather Forecasts Integrated Forecasting System (ECMWF-IFS). As the model output provides mass mixing ratios of different types of aerosol, whereas the ceilometers do not, it is necessary to determine a common physical quantity for the comparison. We have chosen the attenuated backscatter $\beta^{*}$ for this purpose. The $\beta^{*}$ profiles are calculated from the mass mixing ratios of the model output assuming the inherent aerosol microphysical properties. Comparison of the attenuated backscatter averaged between an altitude of $0.2 \mathrm{~km}$ (typical overlap range of ceilometers) and $1 \mathrm{~km}$ in general shows similar annual average values. However, the standard deviation of the difference between model and observation is larger than the average in 8 out of 12 sites.
\end{abstract}

To investigate possible reasons for the differences, we have examined the role of the hygroscopic growth of particles and the particle shape. Our results show that using a more recent particle growth model would result in a $\sim 22 \%$ reduction of particle backscatter for sea salt aerosols, corresponding to a $10 \%$ reduction of the total backscatter signal on average. Accounting for nonspherical dust particles in the model would reduce attenuated backscatter of dust particles by $\sim 30 \%$. As the concentration of dust aerosol is in general very low in Germany, a significant effect on the total backscatter signal is restricted to dust episodes. In summary, consideration of both effects tends to improve the agreement between model and observations but without leading to a perfect consistency.

In addition, a strong Saharan dust event was investigated to study the agreement of the spatiotemporal distribution of particles. It was found that the arrival time of the dust layer and its vertical extent very well agree between model and ceilometer measurements for several stations. This underlines the potential of a network of ceilometers to validate the dispersion of aerosol layers. 


\section{Introduction}

Aerosols are an important constituent of the atmosphere, playing a key role in the Earth's climate and weather system. They influence the Earth's radiation budget directly by absorbing and scattering radiation and indirectly by providing nuclei for cloud condensation. The chemical and physical properties of aerosols depend on their composition and sources. In recent decades, an increasing amount of anthropogenic aerosols has been released into the atmosphere which makes it one of the largest uncertainties in assessments of climate change (IPCC, 2012). Numerous studies have been conducted in recent decades to investigate the relationship between aerosols, air quality, weather and climate (Jones et al., 2001; Stier et al., 2005; Lohmann et al., 2007; Benedetti et al., 2009; Morcrette et al., 2009; Kazil et al., 2010; Wang et al., 2011; Zhang et al., 2012; Forkel et al., 2015; Chan and Chan, 2017; Chan, 2017). These studies mostly rely on model simulations. However, atmospheric processing of aerosols is quite complex, and their physical and chemical properties are highly variable in space and time. Thus, simplifications and assumptions are required with respect to the physics and chemistry of aerosols and the computations of their radiative properties.

The current state of the description of radiative properties of particles in numerical models is elaborated, e.g., by Baklanov et al. (2014). The influence of the description of particle microphysics, including their mixing state, hygroscopic growth and shape, on simulated aerosol optical properties was discussed, e.g., in detail by Curci et al. (2015). Numerical simulations of atmospheric composition require meteorological data and chemical emission inventories as input. Emission inventories of anthropogenic pollutants can be estimated through the "bottom-up" or "top-down" method. The former one relies on statistics of local information, such as road graph, industry location, population density and electricity consumption, together with appropriate emission factors. The latter one uses observations as input and disaggregated to different emission sectors by means of local statistical indicators (van der Gon et al., 2012). Due to the rapid changes of sources, emission inventories might be outdated in specific regions, introducing large uncertainties in the model. Moreover, physical and chemical processes in the atmosphere are parameterized in models due to the intricacy of these processes, leading to additional uncertainties. As a consequence, validation of model output against observational data becomes increasingly important.

The relevance of validation is documented by the establishment of international activities, e.g., the Air Quality Model Evaluation International Initiative (AQMEII; Rao et al., 2011) when up to 20 groups provided model simulations of - among others - particulate matter. Common to almost all validation activities - except for in situ measurements of mass concentrations - is that they require the transformation of prognostic variables of the model, e.g., mass mixing ratios of a number of aerosol components, to variables that can be measured. These are typically optical properties of the aerosols. Validation studies relying on in situ measurements of near-surface concentrations, e.g., from the AirBase and European Monitoring and Evaluation Programme (EMEP) networks, were conducted, e.g., by Solazzo et al. (2012) and Im et al. (2015). Measurements of aerosol optical depth (AOD) are mainly based on the Aerosol Robotic Network (AERONET). Balzarini et al. (2015) compared AOD at 12 AERONET sites and in situ measurements from ground-based networks to investigate the performance of two chemical mechanisms of the Weather Research and Forecasting model with chemistry (WRF-Chem) (Grell et al., 2005; Fast et al., 2006). In the framework of AQMEII-2, modeled single scattering albedo, asymmetry parameter and AOD were also compared to AERONET data (Curci et al., 2015). AOD and Ångström exponents from AERONET as well as AOD from spaceborne measurements were used for validation in the framework of the Monitoring Atmospheric Composition and Climate (MACC)-II reanalysis project (Cuevas et al., 2015). Investigations in how far range-resolved measurements from active remote sensing systems can serve for model validation have been conducted in the last few years only. A combination of the European Aerosol Research Lidar Network (EARLINET) and AERONET data for the Lidar-Radiometer Inversion Code (LIRIC; Chaikovsky et al., 2016) was used by Binietoglou et al. (2015) for 10 selected stations to investigate the accuracy of four dust transport models. Siomos et al. (2017) also used LIRIC and focused on the validation of aerosol mass concentration profiles for 22 cases over Thessaloniki, Greece. Mona et al. (2014) performed an intercomparison on the basis of extinction coefficient profiles from EARLINET data at Potenza, Italy, and the BSC-DREAM8b model covering 310 cases out of 12 years. These studies demonstrated impressively that the exploitation of range-resolved measurements offers new perspectives for validation.

Quantitative range-resolved aerosol parameters can be obtained from advanced lidar measurements. These lidar systems are however expensive in investment and maintenance, and continuous operation is only slowly developing. For these reasons, ceilometers might be a new option, though they are only simple single-wavelength low energy backscatter lidars. On the other hand, they are eye-safe and can be operated continuously and fully automated, therefore making them suitable for setting up extended networks. In recent years, many synoptic observation stations have already been equipped with ceilometers and the number is still growing. Although ceilometers were originally designed for cloud height detection only, recent studies show that ceilometers are also able to measure aerosol profiles (Flentje et al., 2010; Wiegner and Geiß, 2012; Cazorla et al., 2017). If ceilometers are calibrated, the primary output is the so-called attenuated backscatter $\beta^{*}$. Inversion of the signals provides the particle backscatter coefficient $\beta_{\mathrm{p}}$ if the lidar ratio $S_{\mathrm{p}}$ is known. As 
$\beta_{\mathrm{p}}$ in the infrared spectral range is rather insensitive to errors of the lidar ratio $\left(S_{\mathrm{p}}\right)$, this is typically not an issue. In contrast, the derivation of aerosol extinction coefficients $\alpha_{\mathrm{p}}$ may be subject to large uncertainties due to an actually unknown lidar ratio. As a consequence, $\beta^{*}$ or $\beta_{\mathrm{p}}$ are candidates for validating aerosol profiles derived from numerical weather prediction (NWP) models. However, to our knowledge, this approach has not yet been applied.

In this study, for the first time, a comparison of aerosol profiles provided by the Copernicus Atmosphere Monitoring System (CAMS) with long-term measurements of the ceilometer network measurements operated by the German weather service Weather Service (DWD) is presented. CAMS forecasts are quite relevant as it is often used to provide boundary conditions for regional chemistry transport models. In Sect. 2, the ceilometer data and the aerosol description in the model are described. The concept used for the validation is discussed in Sect. 3. The intercomparison discussed in Sect. 4 comprises ceilometer measurements of 1 year (from 1 September 2015 to 31 August 2016) at 12 different stations in Germany and includes investigations of the importance of the numerical description of the hygroscopic growth and shape of the particles. Moreover, the agreement of the spatiotemporal distribution of dust particles during a Saharan dust event is discussed. A summary and suggestions for further studies conclude the paper.

\section{Basis of the intercomparison}

The comparison of "aerosol profiles" derived from weather forecast models and retrieved from ceilometer measurements suffers from the fact that models and measurements do not provide the same physical quantity. In this section, the output of the IFS and the ceilometers is described. This constitutes the basis for the determination of a common quantity for the intercomparison.

\subsection{ECMWF-IFS: aerosol description}

The European Centre for Medium-Range Weather Forecasts Integrated Forecasting System (ECMWF-IFS) is a comprehensive Earth system model. An aerosol and chemistry module is coupled to the ECMWF-IFS by CAMS to provide analysis and forecasts of atmospheric composition (Buizza et al., 1999; Rabier et al., 2000; Bechtold et al., 2008; Drusch et al., 2009; Dutra et al., 2013). In this study, daily forecast data are taken at 00:00 UTC, resulting in a forecast lead time of $0-21 \mathrm{~h}$. In the framework of Global and regional Earth-system Monitoring using Satellite and in-situ data (GEMS), concentrations of aerosol compounds were included as new prognostic variables into IFS (Morcrette et al., 2009; Benedetti et al., 2009). The parameterization of aerosol physics is mainly based on the concept of the LOA/LMD$\mathrm{Z}$ model (Boucher et al., 2002; Reddy et al., 2005). Tropo- spheric aerosols are introduced in the model, including two natural types, sea salt and dust, and three other types with significant anthropogenic contribution, i.e., sulfate, organic matter and black carbon. Stratospheric and volcanic aerosols are not considered in the present version.

The emission of sea salt and dust is controlled by the wind speed at a height of $10 \mathrm{~m}$. Following the findings of Engelstaedter and Washington (2007), it was suggested by Morcrette et al. (2008) to also consider the gustiness of the wind. The sources for the anthropogenic aerosols are taken from external emission inventories, i.e., the Emissions Database for Global Atmospheric Research (EDGAR, 2013), the Global Fire Emissions Database (GFED; van der Werf et al., 2010) and the Speciated Particulate Emission Wizard (SPEW) were used in the simulation. A detailed description of the sources of aerosols can be found in Dentener et al. (2006).

The abovementioned five aerosol types are further subdivided: natural aerosols are categorized into three different size bins each, whereas carbonaceous aerosols are differentiated into hydrophobic and hydrophilic particles. Sulfur is presented in the model in two forms, sulfur dioxide $\left(\mathrm{SO}_{2}\right)$ and sulfate $\left(\mathrm{SO}_{4}\right)$; the former one was assumed in gas phase, while the latter is assumed in particulate phase. In total, the mass mixing ratios $m$ of 11 different aerosol types (see Table 1) are introduced as prognostic variables in the model.

Mass mixing ratios of these 11 types of aerosols are provided with a temporal resolution of $3 \mathrm{~h}$. The horizontal resolution of the original CAMS model output used in this study is approximately $0.7^{\circ} \times 0.7^{\circ}$. The data are then transformed to one of the following spatial coordinate systems: spherical harmonics (SH), Gaussian grid (GG) or latitude/longitude (LL). From this archive, we retrieved the data on a regular latitude/longitude grid with $1^{\circ} \times 1^{\circ}$ resolution. The vertical dimension of the model is separated into 60 pressure-sigma levels. Optical properties of aerosol, e.g., extinction coefficient, aerosol optical depth and backscatter coefficient, are not included in the output of the model but calculated offline from the model output of aerosol mass mixing ratio. A more detailed description of the treatment of the aerosols can be found in Morcrette et al. (2009).

\subsection{Aerosol microphysical properties}

To determine the interaction between aerosols and radiation, the optical properties of each type are calculated for the shortwave and longwave spectral range. In this context, also the change of the optical properties with relative humidity is considered. In this study, we adapted the aerosol microphysical properties assumed in the previous study (Reddy et al., 2005), as the resulting aerosol optical depths were reported to agree well with observations (Morcrette et al., 2009). A brief description of the aerosol microphysical properties relevant for this study is presented in the following. 
The particle size distribution is assumed to be lognormal with three parameters: $\sigma_{\mathrm{g}, i}$ as the "geometric standard deviation", i.e., the width of the distribution, $r_{0, i}$ as the modal radius and $N_{i}$ as the total number concentration of particles of mode $i$. Thus, the size distribution (with $r$ as the particle's radius) consisting of $k$ modes is described by Eq. (1):

$N(r)=\sum_{i=1}^{k} \frac{N_{i}}{\sqrt{2 \pi} \cdot \ln \sigma_{\mathrm{g}, i} \cdot r} \cdot \exp \left\{-\left(\frac{\ln r-\ln r_{0 i}}{\sqrt{2} \cdot \ln \sigma_{\mathrm{g}, i}}\right)^{2}\right\}$,

with normally $k \leq 3$.

All aerosol types except sea salt are assumed to have a monomodal lognormal distribution $(k=1)$. Only for sea salt, a bimodal lognormal distribution is assumed $(k=2)$. The parameters $\sigma_{\mathrm{g}}$ and $r_{0}$ characterizing each aerosol type are listed in Table 1. They are based on Reddy et al. (2005) and valid for dry particles.

For the sulfate, organic matter and black carbon aerosol types $\sigma_{\mathrm{g}}=2.0$ are selected, and the modal radii $r_{0}$ are $0.0355,0.0355$ and $0.0118 \mu \mathrm{m}$, respectively (Boucher and properties of hydrophilic and hydrophobic carbonaceous aerosols are assumed to be the same.

Dust aerosols are also described by a monomodal lognormal size distribution with $r_{0}=0.29 \mu \mathrm{m}$ and $\sigma_{\mathrm{g}}=2.0$ (Guelle et al., 2000) but split into three size bins. The limits are 0.03$0.55 \mu \mathrm{m}$ (fine mode), $0.55-0.9 \mu \mathrm{m}$ (accumulation mode) and 0.9-20.0 $\mu \mathrm{m}$ (coarse mode), respectively. These boundaries are chosen so that approximately $10 \%, 20 \%$ and $70 \%$ of the total mass of the aerosols are in each of the size bins (Morcrette et al., 2009).

Sea salt aerosols as the second class of natural aerosols are also represented by three size bins. For dry sea salt aerosol, their limits are slightly different and set to 0.015 , $0.251,2.515$ and $10.060 \mu \mathrm{m}$. In contrast to the dust aerosols, a bimodal lognormal distribution with $r_{0}=0.1002$ and $1.002 \mu \mathrm{m}$, and $\sigma_{\mathrm{g}}=1.9$ and 2.0 (O'Dowd et al., 1997) is assumed. The number concentrations $N_{1}$ and $N_{2}$ of the first and second modes are 70 and $3 \mathrm{~cm}^{-1}$, respectively.

The refractive index of sea salt is assumed to be wavelength independent (Shettle and Fenn, 1979). For all other aerosol types, a wavelength dependence is assumed and tabulated for 44 wavelengths between $\lambda=0.28$ and $4.0 \mu \mathrm{m}$, with values taken from Boucher and Anderson (1995); Köpke et al. (1997) and Dubovik et al. (2002). The aerosol microphysical and optical properties at $1064 \mathrm{~nm}$, the wavelength of the ceilometers of the DWD network, are listed in Table 1. Other relevant wavelengths for ceilometer and lidar applications are listed in Table in the Appendix.

In the case of hygroscopic growth of particles, their microphysical properties change. Typically, this effect is parameterized by an increasing modal radius and limits of integration over the size distribution, whereas the width of the distribution $\sigma_{\mathrm{g}}$ is assumed to remain unchanged. The latter approximation is certainly a simplification but frequently used. Anderson, 1995; Köpke et al., 1997). The microphysical

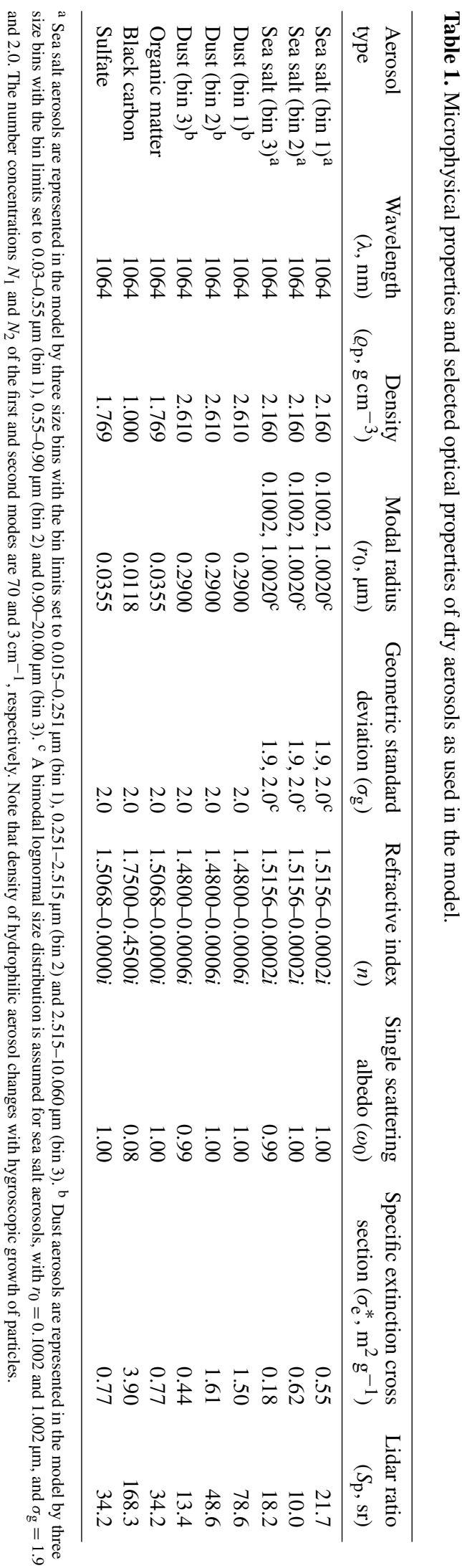

Geosci. Model Dev., 11, 3807-3831, 2018 


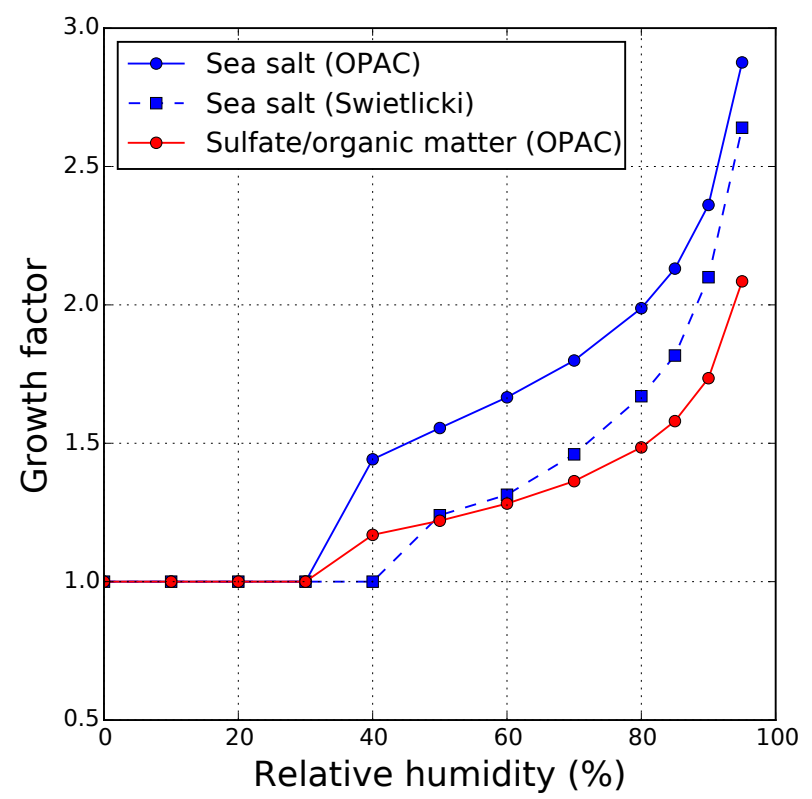

Figure 1. Hygroscopic growth factors of particle radius of sea salt, sulfate and hydrophilic organic matter aerosols as a function of relative humidity. Sulfate and hydrophilic organic matter share the same growth factor in the model (red curve). Growth factors of sea salt obtained from Swietlicki et al. (2008) are also shown for reference.

Hygroscopic growth is considered for sulfate, hydrophilic organic matter and sea salt; see Fig. 1. It is parameterized by growth factors, defined as the ratio between the radius of the wet and dry particle $\left(r / r_{\text {dry }}\right)$ and taken from the Optical Properties of Aerosols and Clouds (OPAC) database (Hess et al., 1998). For sulfate and hydrophilic organic matter, the same factors are used. Especially for a relative humidity above $70 \%$, the growth is strong, whereas no growth is assumed when the relative humidity is below $30 \%$. The refractive index $n$ and density $\varrho$ of wet particles is taken from a look-up table with mixing rules following Hess et al. (1998).

To reduce computational time, the optical properties of hygroscopic aerosols are precalculated for 12 discrete relative humidity levels $(0 \%, 10 \%, 20 \%, 30 \%, 40 \%, 50 \%, 60 \%$, $70 \%, 80 \%, 85 \%, 90 \%$ and $95 \%)$ and stored in a look-up table. It is important to note that sea salt aerosols are emitted and transported as wet aerosols in the model with properties equivalent to $80 \%$ relative humidity. Subsequently, the model-reported mass mixing ratios of sea salt are converted back to dry aerosols. This conversion is achieved by dividing the model-reported mass mixing ratios by the mass growth factor at $80 \%$ relative humidity. The hygroscopic growth effect is then applied to the dry sea salt aerosols to determine the actual optical properties.

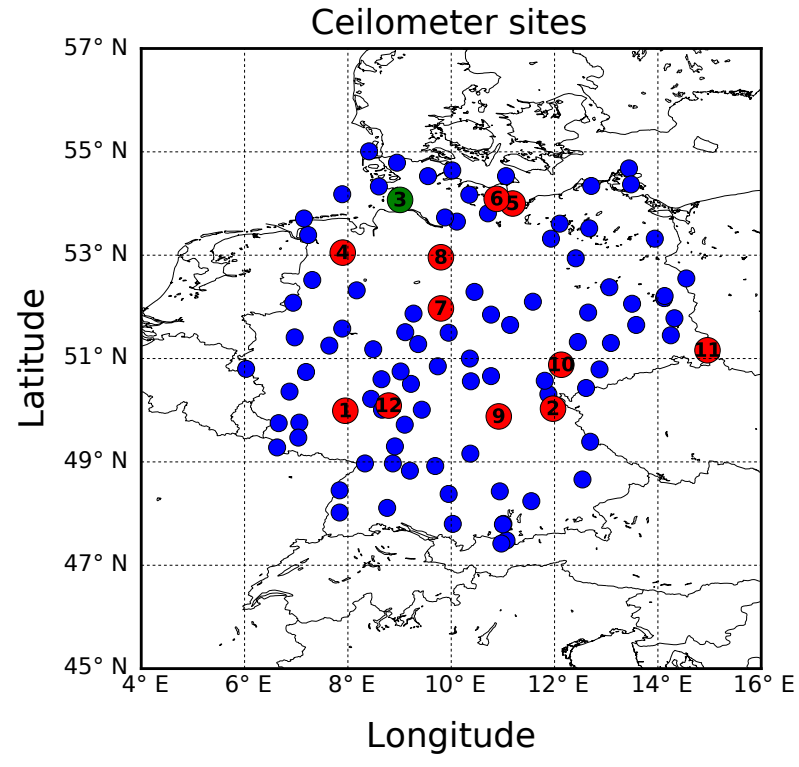

Figure 2. Location of the German weather service ceilometer sites at the end of 2017. The red spots indicate the ceilometer sites within $20 \mathrm{~km}$ of IFS model grid point while the blue markers represent the rest of the network. Note that some of the sites are not in operation during the period of study and therefore not included in this study. Elpersbüttel (see Sect. 4) is indicated in green. More detailed information of the ceilometer sites can be found in Table 2 .

\subsection{The ceilometer network}

In recent years, DWD has equipped a number of synoptic observation stations with Lufft (previously Jenoptik) ceilometers (CHM15k) to establish a ceilometer network (http:// www.dwd.de/ceilomap, last access: 1 October 2016). By the end of 2016, 100 ceilometers were put into operation in Germany. The locations of the ceilometer sites are indicated in Fig. 2. The ceilometer network is still expanding in order to have a better spatial coverage. The ceilometers are eye-safe and fully automated systems which allow unattended operation on a 24/7 basis (Wiegner et al., 2014). They are suitable for monitoring aerosol layers (e.g., volcanic ash; see Flentje et al., 2010), validating meteorological and chemistry transport models (see, e.g., Emeis et al., 2011), and are foreseen for data assimilation (e.g., Wang et al., 2014; Geisinger et al., 2017).

The CHM15k ceilometer is equipped with a diodepumped Nd:YAG laser emitting laser pulses at $1064 \mathrm{~nm}$. The typical pulse energy of the laser is about $8 \mu \mathrm{J}$ with a pulse repetition frequency of $5-7 \mathrm{kHz}$. Backscattered photons are collected by the telescope through a narrow band interference filter and measured by an avalanche photodiode running in photon counting mode. The received backscatter signals are stored in 1024 range bins with a resolution of $15 \mathrm{~m}$; the temporal resolution is set to $15 \mathrm{~s}$. The signals are corrected for incomplete overlap by a correction func- 
tion provided by the manufacturer. As ceilometers are singlewavelength backscatter lidars; the received signals follow the well-known lidar equation. Calibration is required to retrieve quantitative results.

For the intercomparison of ceilometer measurements and modeled aerosol profiles, we only consider sites within $20 \mathrm{~km}$ from a model grid point. This criterion results in a selection of 12 stations. Their location (latitude, longitude, altitude) together with their distance from the nearest IFS grid point are summarized in Table 2.

\section{Concept of intercomparison}

As mentioned above, profiles of mass mixing ratios cannot directly be compared to "ceilometer profiles". The latter can be expressed as particle backscatter coefficient $\beta_{\mathrm{p}}(z)$ or as attenuated backscatter $\beta^{*}(z)$ :

$\beta^{*}(z)=\beta(z) \exp \left\{-2 \int_{0}^{z} \alpha\left(z^{\prime}\right) \mathrm{d} z^{\prime}\right\}$,

with $z$ being the height, $\beta$ and $\alpha$ the backscatter and the extinction coefficient, respectively. From the model results, $\beta^{*}(z)$ and $\beta_{\mathrm{p}}(z)$ can be calculated straightforwardly and the computational effort is comparable. Retrieval of both $\beta^{*}(z)$ and $\beta_{\mathrm{p}}(z)$ from ceilometer measurements requires the calibration of the ceilometer, i.e., the determination of the lidar constant $C_{\mathrm{L}}$ (also known as calibration factor). The derivation of $\beta_{\mathrm{p}}(z)$ requires furthermore an inversion of the signals (e.g., Klett, 1981; Fernald, 1984) relying on the assumption of a particle lidar ratio $S_{\mathrm{p}}$, which depends on the aerosol composition. Consequently, additional uncertainties are introduced. It can be expected that the relative error of $\beta_{\mathrm{p}}$ is as good as approximately $15 \%$ for specific Lufft ceilometers (Wiegner and Geiß, 2012) but can also exceed $30 \%$. Note that water vapor absorption must be taken into account for ceilometers operating near $910 \mathrm{~nm}$; otherwise, an additional uncertainty depending on the water vapor content and the spectrum of the emitted laser radiation is introduced (Wiegner and Gasteiger, 2015). Fortunately, this does not apply for the ceilometers of the DWD, which measure at $1064 \mathrm{~nm}$. However, this effect may be relevant for other ceilometer networks.

For these reasons, and because weather services are in favor of the attenuated backscatter for intercomparisons, we chose $\beta^{*}(z)$ as the common quantity in this study. In this section, the procedures to derive attenuated backscatter from model simulations and ceilometer measurements are presented in detail.

\subsection{Attenuated backscatter from model output}

The model outputs consist of the mass mixing ratios $m_{\mathrm{p}, i}$ of the 11 aerosol types, and no optical property of aerosol is provided. Therefore, we have to convert the model output to attenuated backscatter to compare to ceilometer measurements. In a first step, the mass mixing ratios of each aerosol type are converted to mass concentrations $c_{\mathrm{p}, i}$ by multiplying with the air density $\varrho_{\text {air }}$ as shown in Eq. (3), with the air density calculated from the temperature and pressure profiles of the IFS model.

$c_{\mathrm{p}, i}(z)=\varrho_{\text {air }}(z) m_{\mathrm{p}, i}(z) \quad$ for $i=1,2, \ldots, 11$

The particle extinction coefficient $\alpha_{\mathrm{p}, i}$ of each aerosol type $i$ is calculated using fundamental relations of scattering theory as shown in Eq. (4):

$\alpha_{\mathrm{p}, i}(z)=\pi \int_{r_{1}}^{r_{2}} r^{2} Q_{\mathrm{ext}, i}(z) \frac{\mathrm{d} N_{i}(r)}{\mathrm{d} r} \mathrm{~d} r$,

where $Q_{\text {ext, } i}$ is the extinction efficiency, and $r_{1}$ and $r_{2}$ are the lower and upper limits of the size bin. The particle backscatter coefficient is defined in a similar way:

$\beta_{\mathrm{p}, i}(z)=\pi \int_{r_{1}}^{r_{2}} r^{2} Q_{\mathrm{bsc}, i}(z) \frac{\mathrm{d} N_{i}(r)}{\mathrm{d} r} \mathrm{~d} r$,

with $Q_{\mathrm{bsc}, i}$ being the scattering efficiency multiplied by the phase function at $180^{\circ}$. For convenience, it is common to use the lidar ratio $S_{\mathrm{p}, i}$,

$S_{\mathrm{p}, i}(z)=\frac{\alpha_{\mathrm{p}, i}(z)}{\beta_{\mathrm{p}, i}(z)}$,

to calculate particle backscatter coefficients from extinction coefficients.

The extinction efficiencies and lidar ratios of each aerosol type are calculated applying the size distribution $\mathrm{d} N(r) / \mathrm{d} r$ and the refractive index $n$ of the particles, and by means of an appropriate scattering theory: for spherical particles, the Mie theory is applied; for nonspherical particles, a suite of approaches is available, with the $T$ matrix (Mishchenko and Travis, 1998) being the most frequently used option. As reference, we use the Lorenz-Mie scattering algorithm (Mishchenko et al., 1999) even for nonspherical aerosol types as dust but include a detailed discussion of the influence of particle shape on lidar-related optical properties in Sect. 4.1.2. In order to retrieve the optical properties of the 11 aerosol types, integration was performed according to the given size bins; otherwise, the upper limit was set to $r=20 \mu \mathrm{m}$. In the case of hygroscopic growth of particles, their physical size, refractive index and density change according to the look-up table mentioned above.

The conversion from the mass concentration to the extinction coefficient can now readily be achieved by using the mass extinction coefficient $\eta_{\alpha, i}$ (given, e.g., in $\mathrm{m}^{2} \mathrm{~g}^{-1}$ ),

$\eta_{\alpha, i}=\frac{\alpha_{\mathrm{p}, i}}{c_{\mathrm{p}, i}}=\frac{3 \int_{r_{1}}^{r_{2}} r^{2} Q_{\mathrm{ext}, \mathrm{i}}\left(\mathrm{d} N_{i}(r) / \mathrm{d} r\right) \mathrm{d} r}{4 \varrho_{\mathrm{p}} \int_{r_{1}}^{r_{2}} r^{3}\left(\mathrm{~d} N_{i}(r) / \mathrm{d} r\right) \mathrm{d} r}$, 
in the radius interval of the corresponding size bin from $r_{1}$ to $r_{2}$. Finally, the extinction and backscatter coefficients of each aerosol type are determined - with consideration of Eq. (6) according to

$\alpha_{\mathrm{p}, i}=c_{\mathrm{p}, i} \eta_{\alpha, i}$

$\beta_{\mathrm{p}, i}=c_{\mathrm{p}, i}\left(\frac{\eta_{\alpha, i}}{S_{\mathrm{p}, i}}\right)=c_{\mathrm{p}, i} \eta_{\beta, i}$.

Here, $\eta_{\beta, i}$ is the factor converting mass concentration to backscatter coefficient (of aerosol type $i$ ). The contribution of the air molecules is determined from the Rayleigh theory. We use the following approximation for the extinction coefficient $\alpha_{\mathrm{m}}\left(\right.$ in $\left.\mathrm{km}^{-1}\right)$ :

$\alpha_{\mathrm{m}}(z, \lambda)=8.022 \times 10^{-4} \varrho_{\text {air }}(z) \lambda^{-4.08}$,

with the air density given in $\mathrm{kg} \mathrm{m}^{-3}$ and the wavelength $\lambda$ in $\mu \mathrm{m}$. The molecular lidar ratio $S_{\mathrm{m}}$ is known to be

$S_{\mathrm{m}}=\frac{\alpha_{\mathrm{m}}}{\beta_{\mathrm{m}}} \approx \frac{8 \pi}{3}$.

Finally, we have to take all contributions into account, i.e., the (total) extinction coefficient $\alpha$ is determined according to

$\alpha=\alpha_{\mathrm{m}}+\sum_{i=1}^{11} \alpha_{\mathrm{p}, i}+\alpha_{\mathrm{w}}$,

and the (total) backscatter coefficient is

$\beta=\beta_{\mathrm{m}}+\sum_{i=1}^{11} \beta_{\mathrm{p}, i}$.

Ultimately, the attenuated backscatter $\beta^{*}(z)$ can be calculated as described in Eq. (2). Note that the effective water vapor absorption coefficient $\alpha_{\mathrm{w}}$ must only be considered in Eq. (11) if model results shall be compared to ceilometers operating in the spectral range around $910 \mathrm{~nm}$ (Wiegner and Gasteiger, 2015). This is, e.g., the case if Vaisala ceilometers were applied.

To increase the efficiency of the computations, $\eta_{\alpha, i}$ and $S_{\mathrm{p}, i}$ are precalculated. An overview of aerosols in dry conditions for the ceilometer wavelength $(1064 \mathrm{~nm})$ is given in Table 1. The wavelengths corresponding to Nd:YAG lasers used for aerosol remote sensing (355, 532 and $1064 \mathrm{~nm})$; the widely used Vaisala ceilometers $(910 \mathrm{~nm})$ and the "typical wavelength" for radiative transfer calculations in the shortwave spectral range $(550 \mathrm{~nm})$ are also shown in Table in the Appendix. Note that the lidar ratios of some aerosol types differ from values published by, e.g., Groß et al. (2015) because of the limits of the particle size bins.

\subsection{Attenuated backscatter from ceilometers}

Attenuated backscatter $\beta^{*}$ can be derived from the background corrected ceilometer signals $P$ if the system has been
Table 2. Ceilometer sites within a distance of $20 \mathrm{~km}$ to the nearest IFS model grid point; altitude is given in meters above mean sea level. The distance to the nearest model grid point (in $\mathrm{km}$ ) is given in the last column.

\begin{tabular}{llrrrr}
\hline No. & Site & $\begin{array}{r}\text { Latitude } \\
\left({ }^{\circ} \mathrm{N}\right)\end{array}$ & $\begin{array}{r}\text { Longitude } \\
\left({ }^{\circ} \mathrm{E}\right)\end{array}$ & $\begin{array}{r}\text { Altitude } \\
(\mathrm{m})\end{array}$ & $\begin{array}{r}\text { Distance } \\
(\mathrm{km})\end{array}$ \\
\hline 1 & Geisenheim & 49.9866 & 7.9551 & 110 & 3.8 \\
2 & Wunsiedel & 50.0316 & 11.9745 & 622 & 4.0 \\
3 & Elpersbüttel & 54.0692 & 9.0105 & 3 & 7.8 \\
4 & Friesoythe & 53.0500 & 7.9000 & 6 & 8.7 \\
5 & Boltenhagen & 54.0027 & 11.1909 & 15 & 12.5 \\
6 & Pelzerhaken & 54.0893 & 10.8773 & 1 & 12.7 \\
7 & Alfeld & 51.9644 & 9.8072 & 144 & 14.1 \\
8 & Soltau & 52.9605 & 9.7930 & 76 & 14.2 \\
9 & Bamberg & 49.8743 & 10.9206 & 240 & 14.5 \\
10 & Gera & 50.8813 & 12.1289 & 311 & 16.2 \\
11 & Görlitz & 51.1633 & 14.9531 & 240 & 18.0 \\
12 & Offenbach & 50.0894 & 8.7864 & 121 & 18.1 \\
\hline
\end{tabular}

calibrated, i.e., if $C_{\mathrm{L}}$ is known.

$\beta^{*}(z)=\frac{P z^{2}}{C_{\mathrm{L}}}$

It should be emphasized that $C_{\mathrm{L}}$ can vary with time (e.g., caused by aging of components or temperature drifts); thus, calibration should be performed on a regular basis whenever weather conditions permit.

The calibration of the ceilometers of the network is performed routinely by the DWD in a fully automated procedure. It is based on the TOPROF/E-PROFILE Rayleigh calibration routine provide by MeteoSwiss. The calibration relies on the Rayleigh method (Barrett and Ben-Dov, 1967). This is feasible under clear sky conditions and stable aerosol distributions; thus, the applicability depends on the measurement site. In order to avoid adverse influences caused by background sunlight, only nighttime data are used for the calibration. The calibration is based on data averaged over 1$3 \mathrm{~h}$, and only one period is selected per night. Meteorological data used for the Rayleigh calibration are taken from the joint product of the National Centers for Environmental Prediction (NCEP) and the National Center for Atmospheric Research (NCAR) reanalysis data (Kalnay et al., 1996). The derived $C_{\mathrm{L}}$ values are first cleaned for outliers and then smoothed with a 30-day running mean. Calibration constants outside 1.5 times of the 25 th to 75 th percentile range of a 30 -day period are considered as outliers. The smoothed $C_{\mathrm{L}}$ values are finally interpolated to hourly values to be used in Eq. (13). The typical uncertainty of an individual calibration is 15$20 \%$, while the actual error is smaller due to the temporal smoothing. The accuracy of the retrieved $\beta^{*}$ linearly depends on the accuracy of the $C_{\mathrm{L}}$. The monthly variation of $C_{\mathrm{L}}$ is usually less than $5 \%$ and the annual variation is $10-15 \%$. Then, attenuated backscatter $\beta^{*}$ profiles are derived in steps of $3 \mathrm{~h}$, by averaging cloud-free data within $30 \mathrm{~min}$ each before and after the corresponding model time. Longer aver- 
ages are desirable in view of a better signal-to-noise ratio but are critical during daytime if the aerosol distribution is rapidly changing in time. In cases of rain, fog, snowfall and low-level clouds (below $2 \mathrm{~km}$ ), the data are excluded from the evaluation. The data quality flag "sky condition index" from the proprietary software of the ceilometer labels corresponding measurements and cases of reduced window transmission due to droplets on the window. The altitude of the cloud bottom is determined by a complex algorithm based on signal slopes and thresholds; the details are not disclosed to the user.

\section{Results and discussions}

There are several options to discuss the agreement of $\beta^{*}$ profiles from model calculations and ceilometer measurements: criteria include the comparison of absolute values of $\beta^{*}$, the general "shape" of the profiles, the vertical extent of the mixing layer and elevated layers, the vertical structure of the aerosol distribution within the mixing layer and more. A general philosophy on a ranking of different criteria has not yet been developed; e.g., there is no common agreement how to rate profiles when the modeled altitude of an elevated layer is consistent with measurements but the absolute values of $\beta^{*}$ are different. The reason is that the attenuated backscatter of, e.g., elevated Saharan dust or volcanic ash layers may disagree even in the case of the same $\beta_{\mathrm{p}}$ because $\beta^{*}$ does not only depend on the aerosol properties of that layer but is also influenced by the extinction below that layer. In order to minimize this influence, and to consider that part of the atmosphere where most of the aerosols typically reside, we focus in this paper on $\beta^{*}$ of the lowermost part of the troposphere excluding the range of incomplete overlap. All ceilometer data have undergone an individual overlap correction provided by the manufacturer that makes it possible to use profiles for aerosol remote sensing from above approximately $200 \mathrm{~m}$. In the following, we compare $\beta^{*}$ averaged from the typical height of a "reliable overlap correction" (set to $200 \mathrm{~m}$ for all instruments) to $1 \mathrm{~km}$ above ground, henceforward referred to as "near-surface average" $\beta_{\mathrm{ns}}^{*}$. An additional approach of comparison is discussed in Sect. 4.2.

Our investigation is based on measurements from 1 September 2015 to 31 August 2016. Attenuated backscatter profiles are derived from the model results for every $3 \mathrm{~h}$ following the procedure outlined in Sect. 3.1. Ceilometer data are averaged over $1 \mathrm{~h}$ around the model time and profiles with low-level clouds and precipitation are excluded from the analysis. As a consequence, averages consider 240 ceilometer profiles at maximum.

\subsection{Comparison of near-surface attenuated backscatter}

For an overview, the complete time series of the model simulation and ceilometer observation of the near-surface atten- uated backscatter $\overline{\beta_{\mathrm{ns}}^{*}}$ over Elpersbüttel is shown in Fig. 3. This site has been chosen as it is one of the closest to the corresponding model grid point (only $7.8 \mathrm{~km}$ southwest of the ceilometer site; see Table 2) and the orography around the measurement site is quite flat. For Elpersbüttel, we found 1305 cases out of $2920(365 \times 8)$ when intercomparisons could take place. The number of cases varies in a range from 900 (Wunsiedel) to 1763 (Boltenhagen). Results show that the model and ceilometer data both show a similar temporal development with larger $\overline{\beta_{\mathrm{ns}}^{*}}$ during winter and spring. Note that due to cloudy weather during winter the number of useful ceilometer measurements is reduced compared to summer. In cases of low aerosol load, there is a general agreement of both data sets. However, when episodes of large values of $\overline{\beta_{\mathrm{ns}}^{*}}$ are modeled, they typically exceed the observed ones by a factor of 2 or more. This is, e.g., the case in December 2015, beginning of February and April 2016; more detailed investigations are presented in Sect. 4.1.2 and 4.2. The reasons for this overestimate must remain speculative maybe it is due to erroneous assumptions of the aerosol emission or meteorological data. On the other hand, the annual mean derived from the model $\left(\overline{\beta_{\mathrm{ns}}^{*}}=1.35 \times 10^{-3} \mathrm{~km}^{-1} \mathrm{sr}^{-1}\right)$ agrees very well with the corresponding value of $\overline{\beta_{\mathrm{ns}}^{*}}=$ $1.31 \times 10^{-3} \mathrm{~km}^{-1} \mathrm{sr}^{-1}$ from the ceilometer observations at Elpersbüttel. Table 3 summarized the annual mean $\overline{\beta_{\mathrm{ns}}^{*}}$ of both ceilometer measurements and model simulations from all 12 measurement sites. For most of the sites, the model obtains higher values than the ceilometer measurements by $\sim 20 \%$ on annual average. This is still a considerably good agreement. The few exceptions are Bamberg, Boltenhagen and Gera, where the model predicts much lower values than observed. The largest difference of a factor of 1.8 is found for Gera, with measurement and model mean values of $\overline{\beta_{\mathrm{ns}}^{*}}=$ $1.85 \times 10^{-3} \mathrm{~km}^{-1} \mathrm{sr}^{-1}$ and $\overline{\beta_{\mathrm{ns}}^{*}}=1.00 \times 10^{-3} \mathrm{~km}^{-1} \mathrm{sr}^{-1}$, respectively. These stations show larger impacts from the local emissions as they are situated close to the cities. The discrepancy between ceilometer observations and model predictions over these three sites is mainly due to the differences in the spatial coverage. As the model resolution is rather coarse $\left(1^{\circ} \times 1^{\circ}\right)$, the model is underestimating the aerosol concentrations over cities due to the averaging over large grid cells.

For a more detailed analysis, we have calculated the differences $(\Delta)$ between modeled and ceilometer-derived $\overline{\beta_{\mathrm{ns}}^{*}}$ with

$\Delta=\overline{\beta_{\mathrm{ns}}^{*}}(\mathrm{mod})-\overline{\beta_{\mathrm{ns}}^{*}}(\mathrm{obs})$,

for Elpersbüttel (see Fig. 4a). The size of the markers is proportional to the number of ceilometer measurements (up to 240) available for each individual intercomparison. The standard deviation $(\sigma)$ of the difference is $\sigma=1.89 \times$ $10^{-3} \mathrm{~km}^{-1} \mathrm{sr}^{-1}$, i.e., quite large compared to the model mean value of $\overline{\beta_{\mathrm{ns}}^{*}}=1.35 \times 10^{-3} \mathrm{~km}^{-1} \mathrm{sr}^{-1}$. Data points with $|\Delta|>3 \sigma$ are considered as outliers (marked in red in Fig. 4a) and filtered out in the subsequent analysis. The remaining data are then used to recalculate the standard deviation 


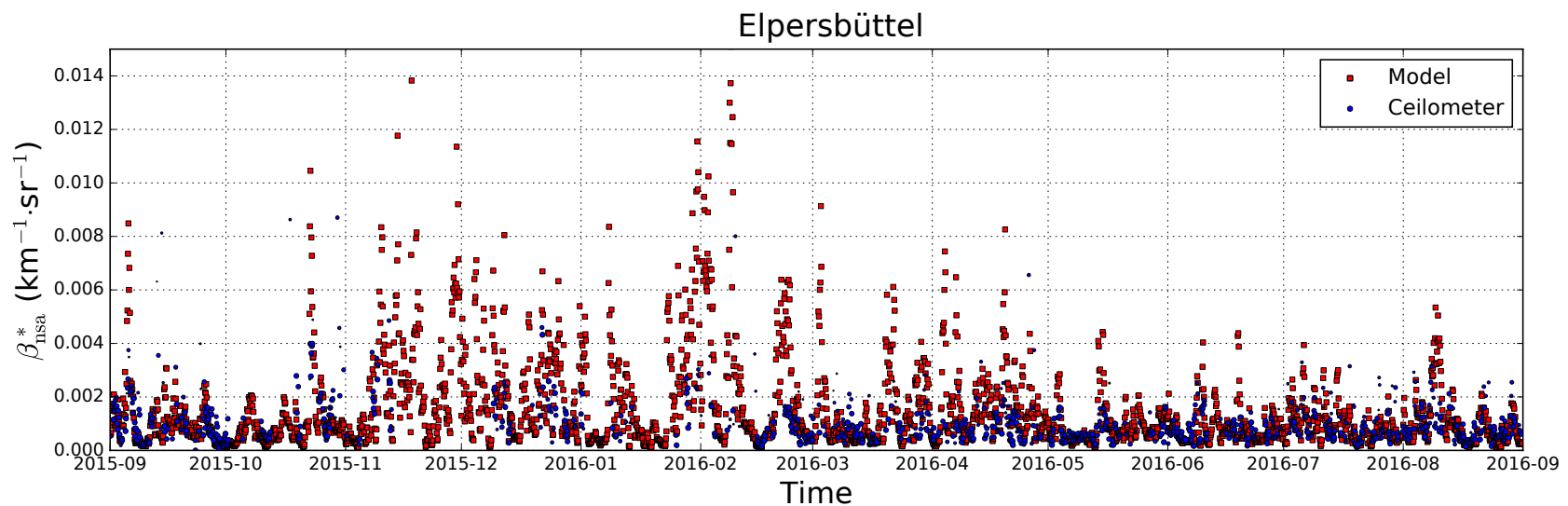

Figure 3. Time series (from 1 September 2015 to 31 August 2016) of the model simulation and ceilometer observation of near-surface attenuated backscatter $\overline{\beta_{\mathrm{ns}}^{*}}$ in $\mathrm{km}^{-1} \mathrm{sr}^{-1}$ over Elpersbüttel with $\overline{\beta_{\mathrm{ns}}^{*}}$ being averaged from $200 \mathrm{~m}$ ("full overlap height") up to $1 \mathrm{~km}$ above ground.

Table 3. Summary of the annual mean $\overline{\beta_{\mathrm{ns}}^{*}}$ of both ceilometer measurements and model simulations from all 12 measurement sites. The standard deviation $(\sigma)$ of the differences is also indicated.

\begin{tabular}{|c|c|c|c|c|}
\hline No. & Site & $\begin{array}{r}\text { Annual average } \\
\text { ceilometer } \overline{\beta_{\mathrm{ns}}^{*}} \\
\left(\times 10^{-3} \mathrm{~km}^{-1} \mathrm{sr}^{-1}\right)\end{array}$ & $\begin{array}{r}\text { Annual average } \\
\text { model } \overline{\beta_{\mathrm{ns}}^{*}} \\
\left(\times 10^{-3} \mathrm{~km}^{-1} \mathrm{sr}^{-1}\right)\end{array}$ & $\begin{array}{r}\text { Standard deviation } \\
\text { of difference } \sigma \\
\left(\times 10^{-3} \mathrm{~km}^{-1} \mathrm{sr}^{-1}\right)\end{array}$ \\
\hline 1 & Geisenheim & 0.91 & 1.12 & 1.25 \\
\hline 2 & Wunsiedel & 1.05 & 0.82 & 0.90 \\
\hline 3 & Elpersbüttel & 1.31 & 1.35 & 1.20 \\
\hline 4 & Friesoythe & 1.31 & 1.20 & 1.58 \\
\hline 5 & Boltenhagen & 1.87 & 1.28 & 1.46 \\
\hline 6 & Pelzerhaken & 1.13 & 1.24 & 1.13 \\
\hline 7 & Alfeld & 1.07 & 1.13 & 1.31 \\
\hline 8 & Soltau & 1.17 & 1.14 & 1.31 \\
\hline 9 & Bamberg & 1.39 & 0.94 & 1.88 \\
\hline 10 & Gera & 1.85 & 1.00 & 1.97 \\
\hline 11 & Görlitz & 0.94 & 0.82 & 0.71 \\
\hline 12 & Offenbach & 0.80 & 0.90 & 0.78 \\
\hline
\end{tabular}

$\left(\sigma=1.20 \times 10^{-3} \mathrm{~km}^{-1} \mathrm{sr}^{-1}\right)$, shown as a horizontal line in Fig. 4a.

To better understand possible reasons for these differences, we have looked into the contribution of different aerosol types. Their relative contributions to $\overline{\beta_{\mathrm{ns}}^{*}}$ as calculated from the model for Elpersbüttel reveal that sea salt is by far the dominating contributor with $61 \%$ (annual mean). Sulfate contributes with $29 \%$ to the near-surface attenuated backscatter, while organic matter (4\%), dust $(3 \%)$ and black carbon $(2 \%)$ only show minor contributions. We have recalculated these contributions separately for two classes: cases of "good" agreement $(|\Delta|<\sigma)$ are shown in Fig. 4b, whereas cases of "bad" agreement $(|\Delta|>\sigma)$ are shown in Fig. 4c. Each aerosol type is color coded as indicated in the legend.

From Fig. 4b, it is immediately visible that for the good agreement sea salt is again the dominating aerosol type: its contribution ranges between $32 \%$ (May 2016) and $85 \%$ (December 2015), with an annual average of $51 \%$. The second important contributor is sulfate aerosols ( $32 \%$ on average), whereas all other types are in the range of a few percent each. Thus, cases of good agreement coincide with a sea salt contribution lower than the mean. Consequently, the contribution of sea salt is above the average when the differences between model and measurement are large $(|\Delta|>\sigma)$. From Fig. 4c, a mean relative contribution of sea salt of $74 \%$ for the "bad" agreement is found. This suggests that the ceilometer and model discrepancy increases with increasing sea salt contribution.

Scatter plots of the ceilometer and the model-derived nearsurface attenuated backscatter for the 12 sites are shown in Fig. 5. The color code represents the relative contribution of sea salt to $\overline{\beta_{\mathrm{ns}}^{*}}$. For most sites, red dots are predominant, indicating the high contribution of sea salt. This phenomenon has 

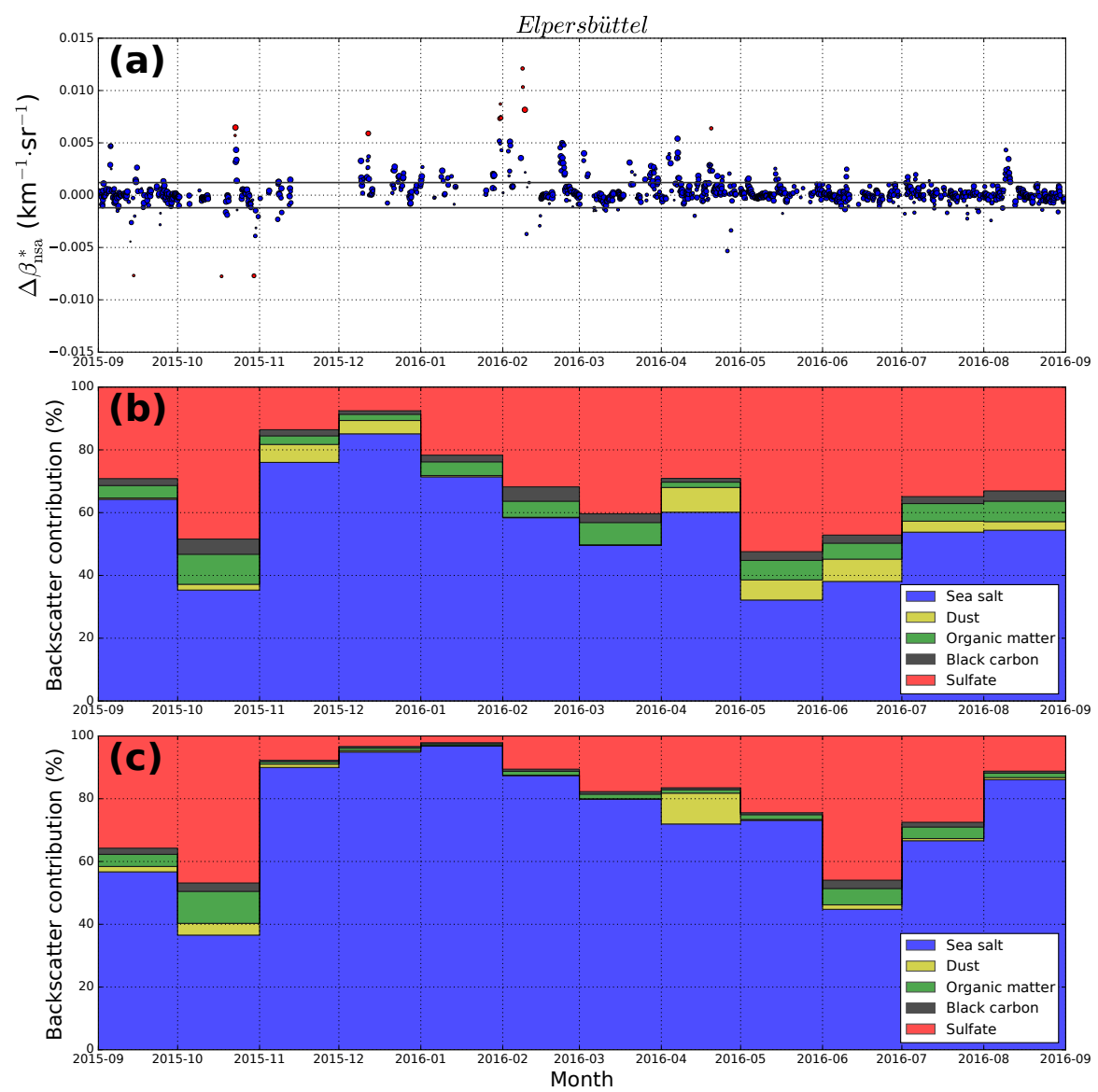

Figure 4. (a) Differences $(\Delta)$ of near-surface attenuated backscatter $\overline{\beta_{\mathrm{ns}}^{*}}$ for Elpersbüttel according to Eq. (14). The horizontal line indicates the standard deviation $(\sigma)$ of the differences. The size of the markers represents the number of ceilometer measurements available for each individual comparison. Differences $|\Delta|>3 \sigma$ are shown in red. (b) Contribution of different aerosol types to $\overline{\beta_{\mathrm{ns}}^{*}}$ for cases with $|\Delta|<\sigma$. (c) Same as panel (b) but for cases with $|\Delta|>\sigma$.

already been discussed in the case of Elpersbüttel. When the sea salt contribution is rather low, the model typically shows lower $\overline{\beta_{\mathrm{ns}}^{*}}$ than the ceilometer retrieval. This is probably due to local emissions which are not well resolved by the model but captured by the ceilometer measurements. The total least squares regression line is based only on intercomparisons when the hourly averaged data contain at least 120 ceilometer profiles ( $30 \mathrm{~min}$ of measurements). The regression is virtually unchanged when the number of valid ceilometer profiles is used as a weight. The slope of the regression line is larger than 1 for all sites, indicating that the model in general results in larger $\overline{\beta_{\mathrm{ns}}^{*}}$. In particular, this is true when the modeled contribution of sea salt is high, e.g., for Friesoythe, Geisenheim and Offenbach. Note that the latter two stations are far from the coast so that the large sea salt contribution seems to be unrealistic. Pearson's correlation coefficient $(R)$ ranges between $R=0.12$ for Bamberg and $R=0.80$ for Elpersbüttel, with no clear dependence on the distance between the model grid point and the ceilometer site.
Reasons for the disagreement can be manifold. One possibility is that the backscatter per unit mass of sea salt is too large in the model. As the optical properties of sea salt critically depend on the hygroscopic growth, we have investigated to which extent this effect might explain the observed differences (see Sect. 4.1.1). Another reason could be that the modeled sea salt concentration is generally overestimated, though the annual averaged contribution to the total AOD ranges from $21 \%$ (Görlitz) to $37 \%$ (Elpersbüttel), which is in a reasonable range. On the other hand, this is much less than the contribution to $\overline{\beta_{\mathrm{ns}}^{*}}$ demonstrating that sea salt is quite effectively backscattering, suggesting that it might partly be substituted by a less effective species to get a better agreement. A further discussion of this topic is however beyond the scope of this paper.

\subsubsection{Influence of hygroscopic growth}

Water uptake by particles has a significant impact on their optical properties as particles can change in size, chemical com- 

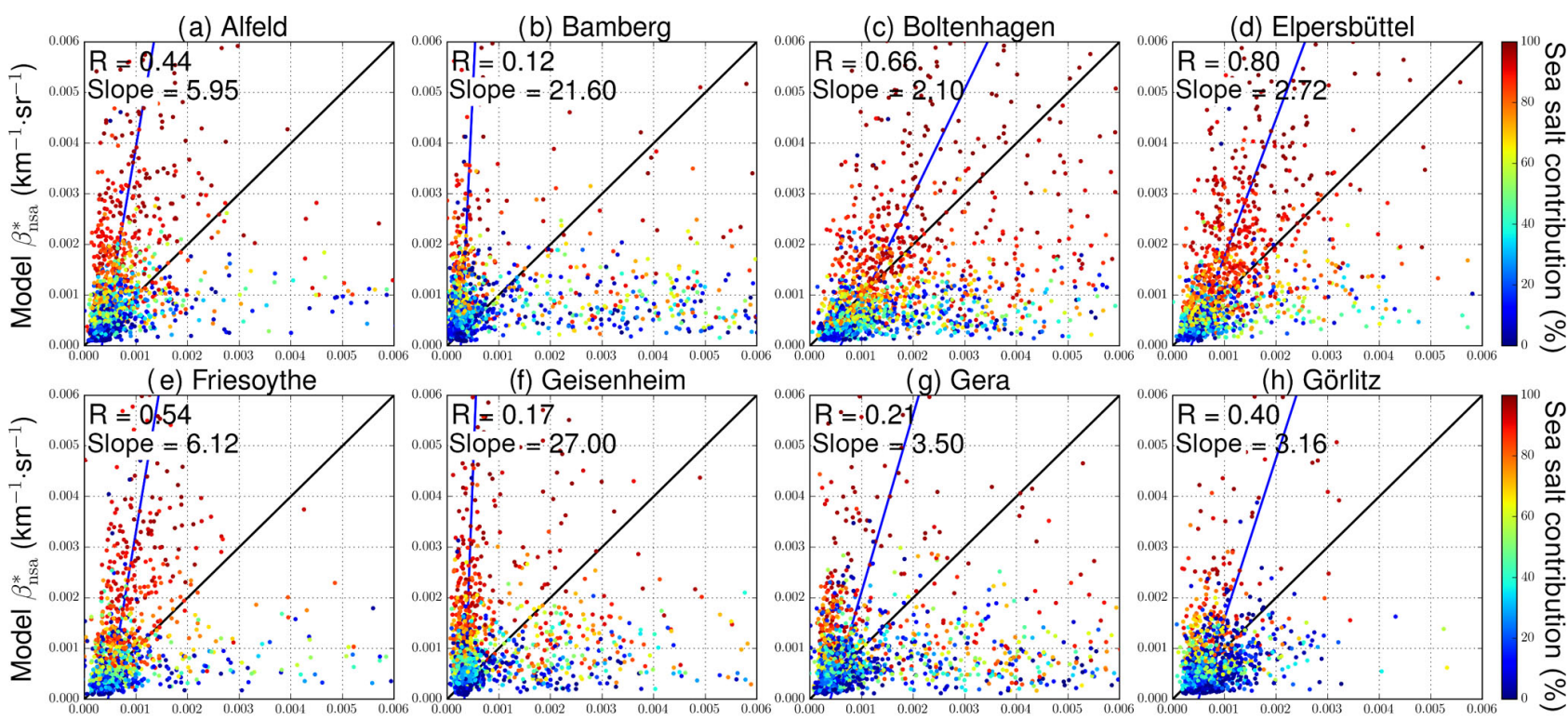

(f) Geisenheim
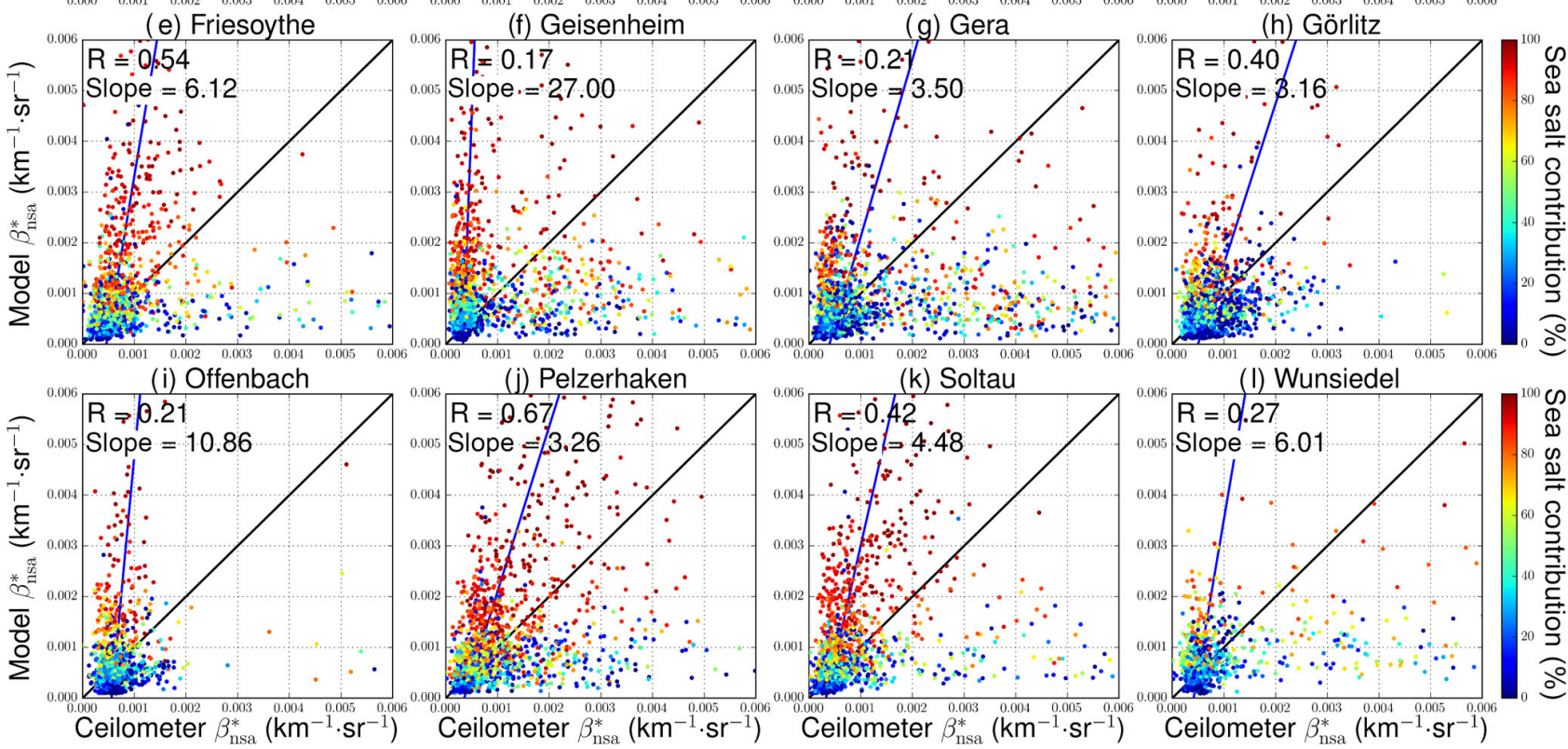

Figure 5. Scatter plots of ceilometer-derived and modeled $\overline{\beta_{\mathrm{ns}}^{*}}$ for the 12 sites listed in Table 2 . The color code represents the relative contribution of sea salt to $\overline{\beta_{\mathrm{ns}}^{*}}$. The blue curve indicates the total least squares regression line of the data points with at least 120 ceilometer profiles, while the black line represents the $1: 1$ reference.

position and refractive index depending on the ambient relative humidity. The assumptions made for their hygroscopic growth have a significant effect on the simulation of ceilometer measurements from the model output. For this reason, we examine the hygroscopic growth effect on the conversion factor $\eta_{\beta}$ for sea salt (see Eq. 8) as the dominating aerosol species (in terms of backscatter) according to the IFS output. We compare two approaches, being aware that more exist (e.g., Chin et al., 2002): the particle hygroscopic growth model implemented in the IFS AOD calculation (based on OPAC, Hess et al., 1998) and a more recent approach (Swietlicki et al., 2008); see Fig. 1. The latter was reported to better match experimental data (Zieger et al., 2013). Compared to OPAC, it shows a less pronounced particle growth with relative humidity. The corresponding conversion factors $\eta_{\beta, \text { ss }}$ of sea salt are shown in Fig. 6a for comparison. Results referring to the three different size bins of the particle model are shown in blue, green and red, respectively. The ratios of the conversion factors from the two approximations $\left(\eta_{\beta, \text { ss }}^{\text {(swie }} / \eta_{\beta, \text { ss }}^{(\text {opac })}\right)$ are shown in Fig. 6b. The conversion factors based on Swietlicki et al. (2008) are on average smaller than those based on the OPAC database. By comparing data calculated with the OPAC database, the alternative set of conversion factors $\eta_{\beta, \text { ss }}^{\text {(swe) }}$ on average reduces backscatter coefficients by a factor of 0.78 . Taking into account that sea salt particles in general contribute more than $50 \%$ to the attenuated backscatter over Germany, overestimating the conversion factor by $22 \%$ on average would already contribute up to an error of more than $10 \%$ of the total backscatter signal.

In order to quantify the effect of a changed hygroscopic growth, we recalculate $\beta^{*}$ from modeled mixing ratios by using the alternative set of conversion factors (Swietlicki et al., 2008) and compare it to ceilometer observations. Analogously to Fig. 5, scatter plots of the ceilometer-derived and modeled $\overline{\beta_{\mathrm{ns}}^{*}}$ for the 12 sites are shown in Fig. 7. Compared to the original model assumptions, modeled attenuated backscatter shows a slightly better agreement with the ceilometer measurements. Although the correlation coefficients between ceilometer and model $\overline{\beta_{\mathrm{ns}}^{*}}$ are nearly unchanged, the slope of the regression lines is on average reduced by $\sim 30 \%$ and agrees better with the $1: 1$ reference line. This effect is more obvious for sites dominated by sea 

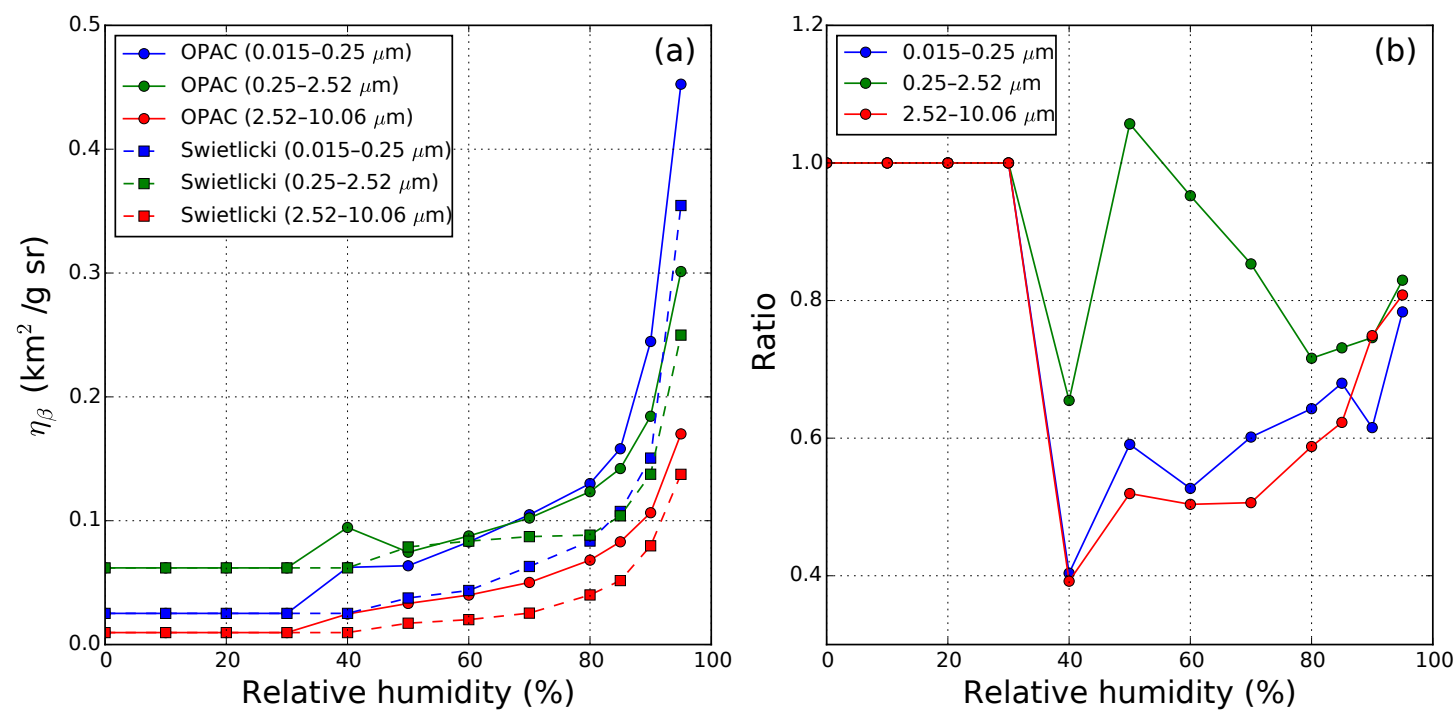

Figure 6. (a) Mass mixing ratio to backscatter coefficient conversion factors $\eta_{\beta, i}$ of sea salt aerosol for the small, medium and large size bins (in blue, green and red) at different ambient relative humidities. Hygroscopic growth factors of sea salt are taken from the model assumption (solid circle curve) and Swietlicki et al. (2008) (dashed square curve). The ratios of mass mixing ratio to backscatter coefficient conversion factors between the hygroscopic growth effects taken from Swietlicki et al. (2008) and OPAC databases are shown in panel (b); ratios smaller than 1 indicate an reduction when using hygroscopic growth from Swietlicki et al. (2008).

salt aerosols in northern Germany, e.g., Boltenhagen, Elpersbüttel, Pelzerhaken and Soltau. The result indicates that the updated hygroscopic growth function leads to a better agreement between model simulations and measurements. However, the model still overestimates $\overline{\beta_{\mathrm{ns}}^{*}}$, indicating that the assumption of a reduced hygroscopic growth alone cannot fully explain the mismatch between model and observations.

\subsubsection{Influence of particle shape}

Besides the hygroscopic growth of hydrophilic aerosols, the shape of particles plays an important role for lidar-related optical properties of particles. Mineral dust particles are typically nonspherical; however, they are often - e.g., in the IFS model - considered as spherical particles in order to simplify the computation. To quantify the influence of the shape, we compared modeled $\beta_{\mathrm{p}}$ and $\beta^{*}$ using either the spherical or the nonspherical assumption. In the case of nonspherical mineral dust particles, spheroids with an aspect ratio distribution measured by Kandler et al. (2009) are assumed in $T$ matrix calculations (Waterman, 1971; Mishchenko and Travis, 1998). Table 4 shows the comparison of their optical properties: it can be seen that nonspherical particles have a significantly larger lidar ratio $S_{\mathrm{p}}$, whereas the specific extinction cross section $\sigma_{\mathrm{e}}^{*}$ is nearly unchanged. As a result, $\beta_{\mathrm{p}}$ is reduced by $15-45 \%$ if nonsphericity is considered, whereas the effect on the AOD is small.

We have also investigated the influence of the treatment of particle shape on the mass-to-backscatter conversion factors $\eta_{\beta}$ of the three dust size bins. For demonstration, one $1 \mathrm{~h}$ profile from a dust episode (3 April 2016, 18:00 UTC; see also next section) is discussed in detail. Attenuated backscatter profiles are shown in Fig. 8a. Ceilometer measurements with the original vertical resolution of $15 \mathrm{~m}$ are shown in light red, whereas the red line shows the ceilometer profile resampled for the model's resolution. Profiles derived from the model output for the spherical and nonspherical assumption are given in blue and green, respectively. Figure 8a clearly demonstrates that the observed decrease of $\beta^{*}$ in the height range between $\sim 1.1$ and $\sim 3.5 \mathrm{~km}$ is very well reproduced by the model simulations. However, the absolute values agree somewhat better if nonsphericity is assumed. This improvement is most pronounced in the lowermost layer where dust is the dominating contributor (see Fig. $8 \mathrm{~b}$ and c); here, the overestimate of $\beta^{*}$ with respect to the ceilometer retrieval is clearly reduced but still in the order of up to a factor of 3 which also implies that the model is overestimating the dust concentration during this episode and/or the aerosol microphysical properties assumed in the forward calculation are different from the actual state. Note that the increased attenuated backscatter at $\sim 8 \mathrm{~km}$ as observed by the ceilometer is due to the presence of clouds. The modeled $\beta_{\mathrm{p}}$ of the different aerosol types is shown in Fig. $8 \mathrm{~b}$ and c, assuming either sphericity or nonsphericity of dust particles. Below $3 \mathrm{~km}$, dust is by far the dominating aerosol type. As can be expected from Table $4, \beta_{\mathrm{p}}$ of the dust component is reduced by 15 $45 \%$ for the three size bins when nonsphericity is considered. For the profile shown, this leads to a reduction of $\sim 33 \%$ of the total particle backscatter coefficient and a better agree- 

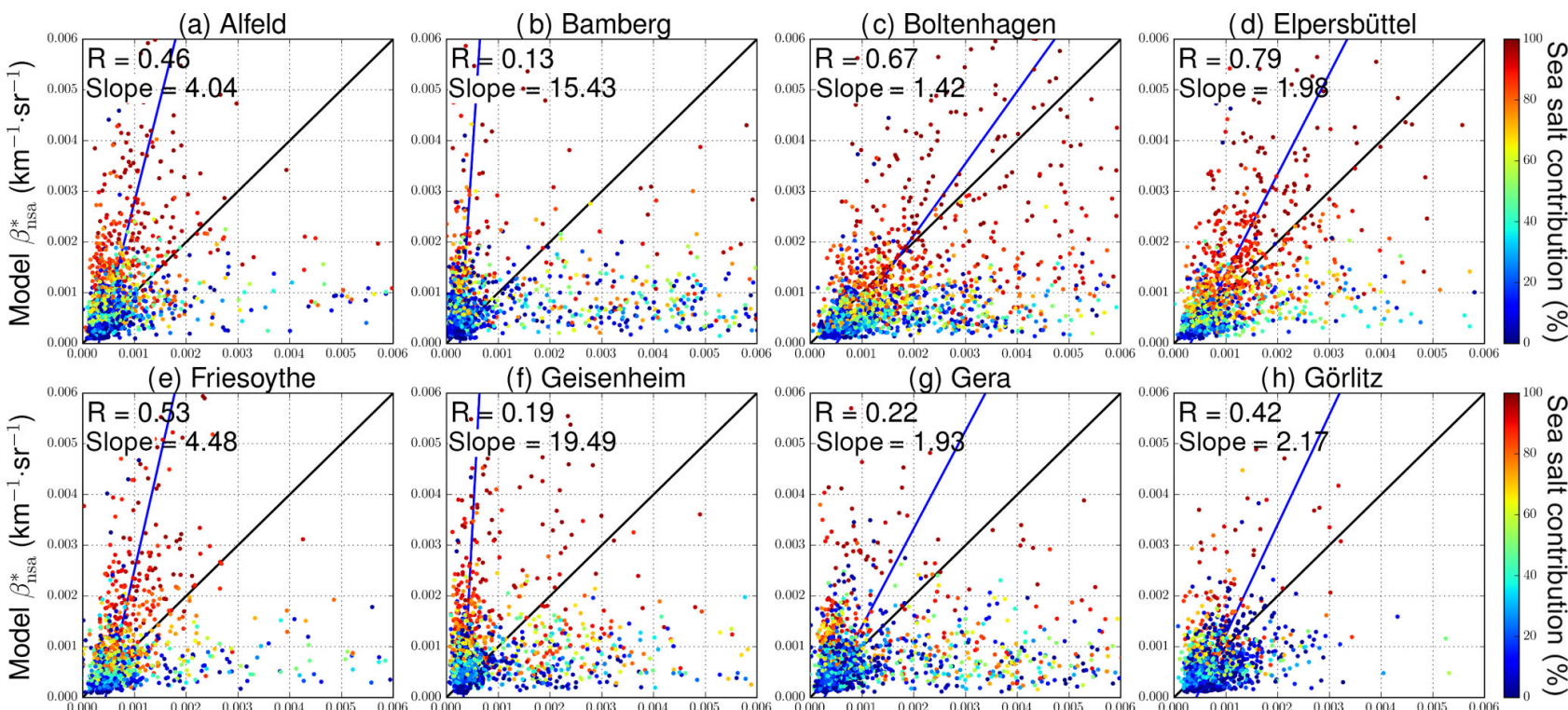

(f) Geisenheim

(g) Gera

(h) Görlitz
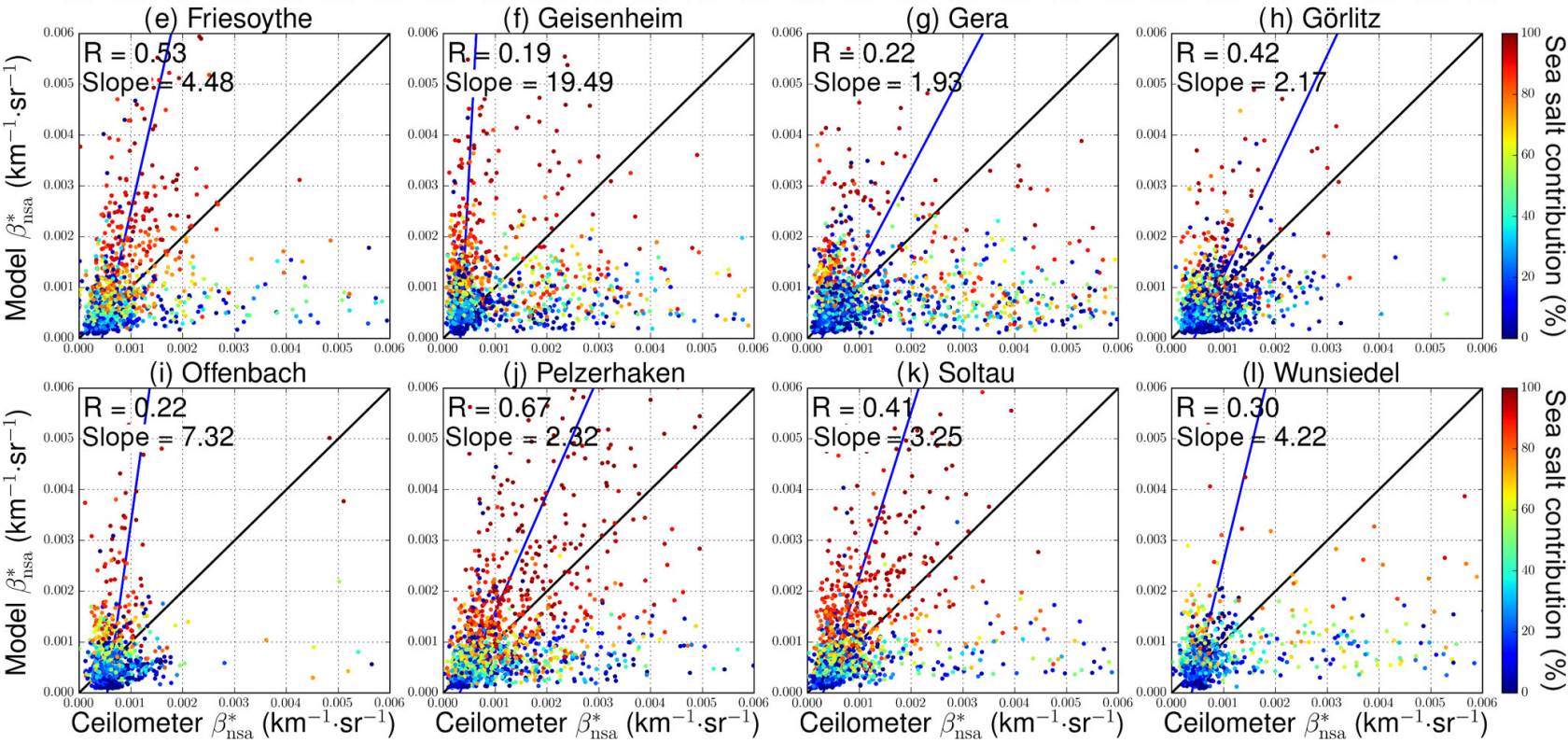

Figure 7. Scatter plots of the ceilometer and model surface attenuated backscatter signals for the 12 sites listed in Table 2 . Model data are converted to attenuated backscatter signal based on hygroscopic growth factors introduced in Swietlicki et al. (2008). Color code represents the relative contribution of sea salt to backscatter signal. The blue curve indicates the total least squares regression line of the data point with at least 120 ceilometer profiles, while the black curve represents the $1: 1$ reference.

Table 4. Comparison of selected optical properties at $1064 \mathrm{~nm}$ of mineral dust particles assuming spherical and nonspherical shapes. Spheroid particles with an aspect ratio distribution measured by Kandler et al. (2009) are assumed for nonspherical dust particles.

\begin{tabular}{lrr|rr|r}
\hline & \multicolumn{2}{|c|}{ Spherical } & Nonspherical & Difference \\
\cline { 2 - 5 } Species & $\begin{array}{r}\text { Specific extinction } \\
\text { cross section } \\
\left(\sigma_{\mathrm{e}}^{*}, \mathrm{~m}^{2} \mathrm{~g}^{-1}\right)\end{array}$ & $\begin{array}{r}\text { Lidar } \\
\text { ratio } \\
\left(S_{\mathrm{p}}, \mathrm{sr}\right)\end{array}$ & $\begin{array}{r}\text { Specific extinction } \\
\text { cross section } \\
\left(\sigma_{\mathrm{e}}^{*}, \mathrm{~m}^{2} \mathrm{~g}^{-1}\right)\end{array}$ & $\begin{array}{r}\text { Lidar } \\
\text { ratio } \\
\left(S_{\mathrm{p}}, \mathrm{sr}\right)\end{array}$ & $\begin{array}{r}\text { in particle } \\
\text { backscatter } \\
\left(\Delta \beta_{\mathrm{p}}, \%\right)\end{array}$ \\
\hline $\begin{array}{l}\text { Dust } \\
(0.03-0.55 \mu \mathrm{m})\end{array}$ & 1.496 & 78.6 & 1.449 & 89.0 & -14.4 \\
$\begin{array}{l}\text { Dust } \\
(0.55-0.90 \mu \mathrm{m})\end{array}$ & 1.611 & 48.6 & 1.602 & 69.4 & -30.3 \\
$\begin{array}{l}\text { Dust } \\
(0.90-20.0 \mu \mathrm{m})\end{array}$ & 0.445 & 13.4 & 0.495 & 26.6 & -44.0 \\
\hline
\end{tabular}

ment with the observations as shown in the left panel. On the other hand, differences of the aerosol optical depth are negligible (less than $1 \%$ ) even during the dust episode. As the concentration of mineral dust aerosol is in general very low in Germany, introducing nonspherical mineral dust in the
IFS model only has a minor impact on the annual average. However, in the case of dust events, nonsphericity should be considered to obtain the best possible agreement. This is also expected for volcanic ash layers which are not yet included in the model. 

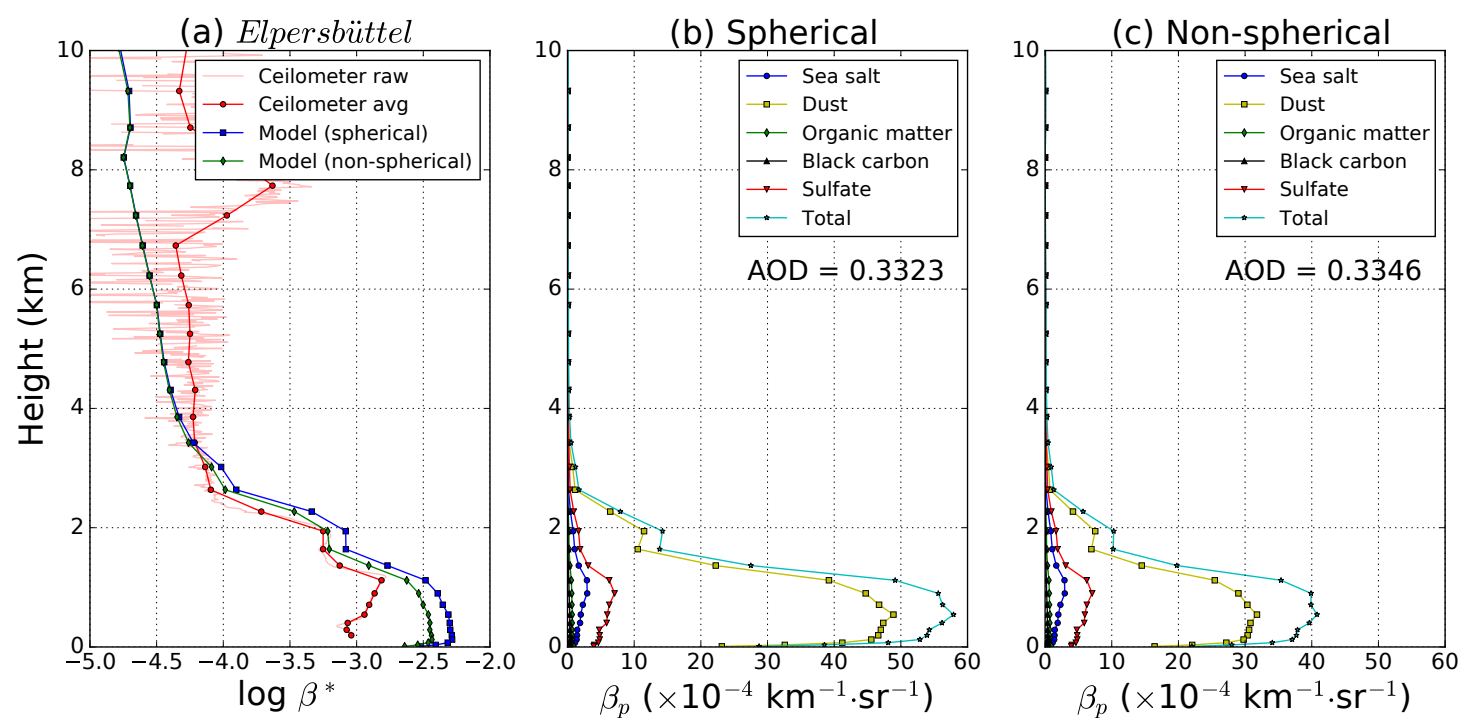

Figure 8. (a) Attenuated backscatter derived from the IFS model and the ceilometer data, respectively, during a dust episode at 18:00 UTC on 3 April 2016 in Elpersbüttel. Model data are converted to $\beta^{*}$ assuming either spherical (blue curve) and nonspherical (green curve) dust particles. Model results of the particle backscatter coefficient $\beta_{\mathrm{p}}$ (light green) together with the contributions of each aerosol type assuming either spherical (b) or nonspherical (c) particle shape. The aerosol optical depth at $1064 \mathrm{~nm}$ is virtually the same (AOD $\approx 0.33$ ).

\subsection{Comparison of the spatiotemporal distribution}

The focus of the previous section was on the agreement of the attenuated backscatter vertically averaged over the lower troposphere. In the following case study of a dust event, we briefly want to outline further options to compare model predictions and measurements of the ceilometer network.

Dust particles are typically a minor contributor to the aerosol abundance in Germany (Beuck et al., 2011; Flentje et al., 2015). On average, they contribute less than $5 \%$ of the total attenuated backscatter according to the IFS model. However, episodes with high concentrations are observed in Germany caused by long-range transport of Saharan dust towards Europe (Ansmann et al., 2003; Stuut et al., 2009; Müller et al., 2009; Wiegner et al., 2011). During the 1 year covered by our study, there were two major dust episodes affecting Germany as a whole: in December 2015 and April 2016. The temporal development of the latter from 2 to 4 April 2016 is shown in Fig. 9 in terms of the modeled dust concentration (in $\mu \mathrm{g} \mathrm{m}^{-3}$ ), averaged over the lowermost kilometer of the troposphere: the dust layer approached Germany from southwest by 2 April and covered large parts of Germany when moving eastwards ( 3 and 4 April 2016). The episode came to an end on 5 April when only Austria was still affected. During this event, all 12 sites showed peak dust contributions of over $50 \%$ of the total $\overline{\beta_{\mathrm{ns}}^{*}}$.

Again we choose Elpersbüttel as an example for the agreement between model and observations. Figure 10a shows the time-height cross section of the attenuated backscatter of the ceilometer, and Fig. 10b shows the corresponding profiles calculated from the model output (blue curve) and retrieved from the ceilometer (red curve). Here, we treat dust particles as nonspherical particles as defined in Sect. 4.1.2. Note that due to cloud filtering some ceilometer profiles stopped at a relatively low altitude.

The ceilometer measurements demonstrate that the dust arrived in Elpersbüttel on 2 April 2016 at 18:00 UTC at the latest (light green signatures in Fig. 10a); however, due to the presence of low-level clouds, the arrival could be up to $4 \mathrm{~h}$ earlier. Pronounced signatures of enhanced backscatter can be observed up to almost $7 \mathrm{~km}$. This is in excellent agreement with the modeled profiles for 18:00 and 21:00 UTC: the aerosol layer is clearly visible up to 6 and $7 \mathrm{~km}$, respectively; even the pronounced aerosol layer up to approximately $1.5 \mathrm{~km}$ is resolved. The absolute values of $\beta^{*}$ are similar with largest differences in the lowermost kilometer. For the time period before 18:00 UTC, the model shows a slightly enhanced $\beta^{*}$ at altitudes above $3 \mathrm{~km}$ that is not visible in the measurements. On the other hand, the vertical extent of the mixing layer is very well reproduced by the model. The enhancement of attenuated backscatter at 4-6 km from 00:00 to 06:00 UTC is due to the presence of clouds.

The temporal development of the attenuated backscatter over Elpersbüttel on the following day, 3 April 2016, is shown in Fig. 11, whereas Fig. 12 shows the contribution of particle backscatter for the five aerosol types from the model. The ceilometer measurements show an pronounced elevated aerosol layer which is clearly separated from the surface aerosol layer before 04:00 UTC. From model simulation, the lower layer primarily contains locally produced 

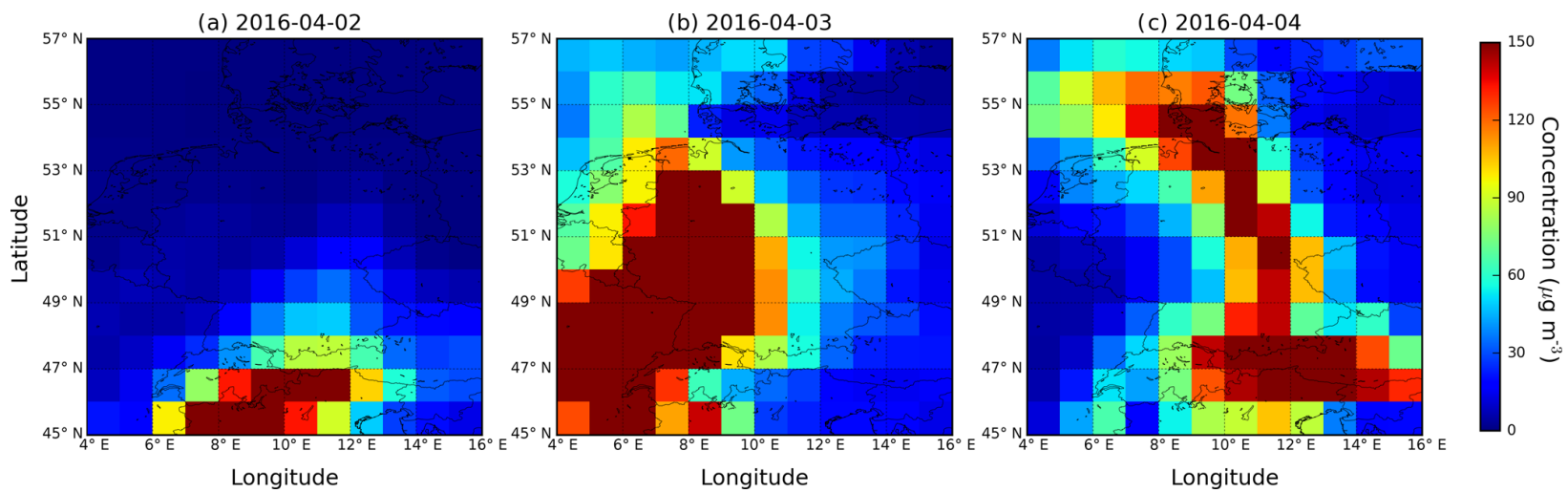

Figure 9. Dust concentration (averaged over the lowermost kilometer of the troposphere, in $\mu \mathrm{g} \mathrm{m}^{-3}$ ) over Germany as predicted from the IFS model: 2 to 4 April 2016 (from left to right), 12:00 UTC.

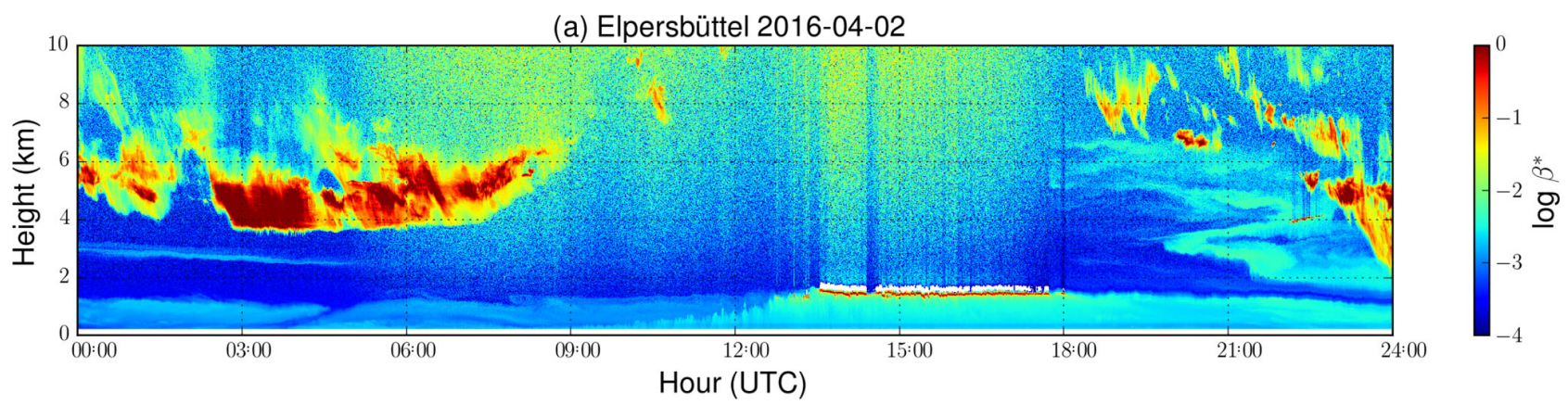

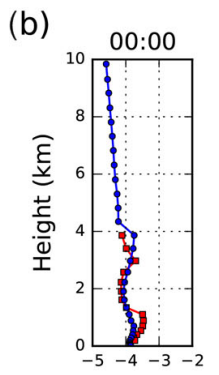

$\log \beta^{*}$

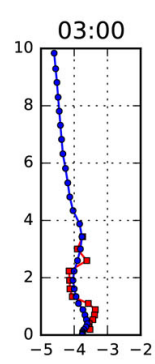

$\log \beta^{*}$

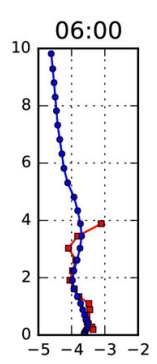

$\log \beta^{*}$

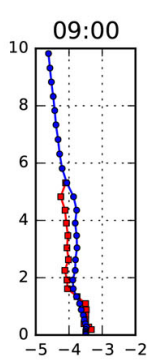

$\log \beta^{*}$

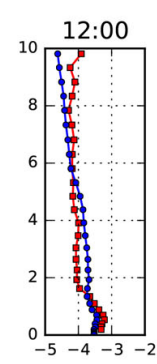

$\log \beta^{*}$

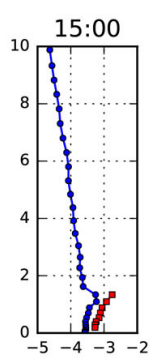

$\log \beta^{*}$

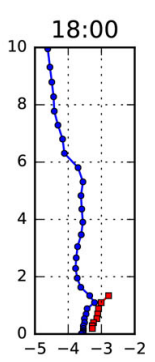

$\log \beta^{*}$

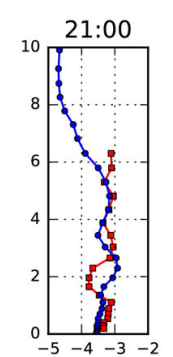

$\log \beta^{*}$

Figure 10. Time series of attenuated backscatter measured by the ceilometer at Elpersbüttel during a dust episode on 2 April 2016 are shown in panel (a). Attenuated backscatter calculated from model simulations (blue curve) is shown in panel (b); ceilometer measurements (red curve) are averaged to model resolution and shown for reference.

particles, i.e., sulfate aerosols, whereas the upper layer is (Saharan) dust. This is plausible but cannot be proven from data of a single-wavelength backscatter ceilometer without depolarization channel. Moreover, from the ceilometer data, it is not possible to determine the top of the aerosol layer due to clouds; nevertheless, measurements at 01:00 and 03:00 UTC suggest that aerosols were present up to approximately $4 \mathrm{~km}$ for the first few hours of the night. The model shows large values of $\beta^{*}$ up to $4 \mathrm{~km}$ until 09:00 UTC with dust as the dominating contributor. For the second half of the day, the dust layer is confined to the lowermost $3 \mathrm{~km}$ according to the model (see Fig. 8). Again, the general agreement of the vertical extent of the aerosol layer is very good. However, it must remain open whether the thin layer at $6-7 \mathrm{~km}$, visible in the modeled $\beta^{*}$ profiles at 09:00 and 12:00 UTC, is real or not. The measurement range of the ceilometer is blocked by clouds in $3 \mathrm{~km}$ altitude, and even under cloud-free conditions the ceilometer might have missed that layer due to the high solar background illumination around noon.

The situation on the last day of the event is shown in Fig. 13. From the ceilometer observations, it can be observed that the elevated aerosol layer disappears at around 19:00 UTC. According to the model simulation, the dust event over Elpersbüttel ended on 4 April 2016 at 18:0021:00 UTC. This is in perfect agreement with the ceilometer's attenuated backscatter profile. However, further valida- 


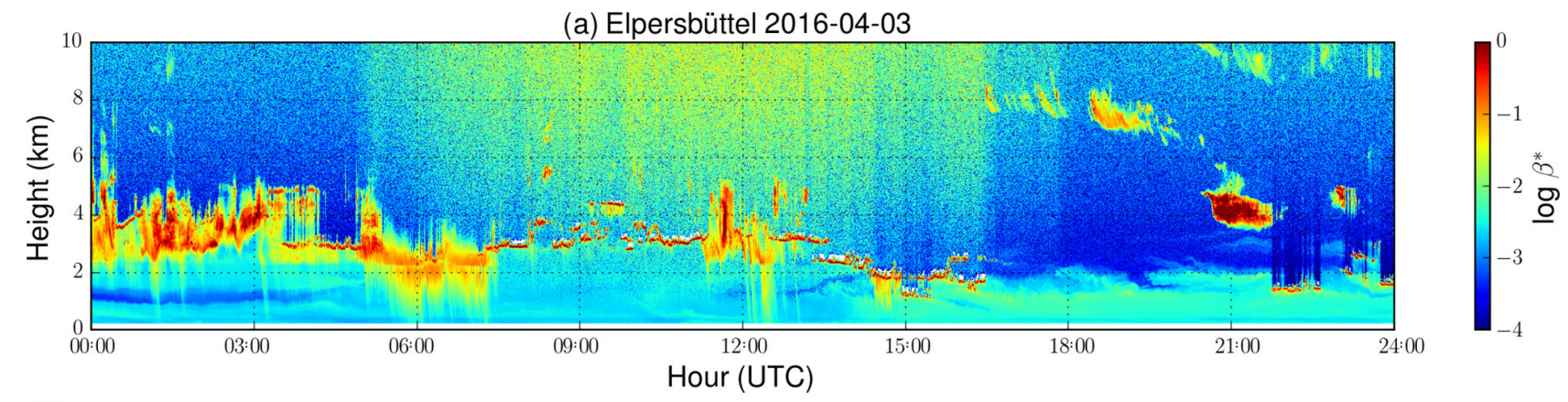

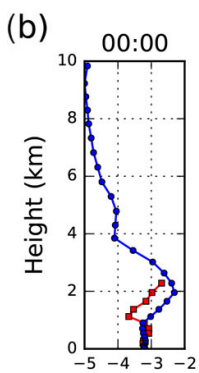

$\log \beta^{*}$

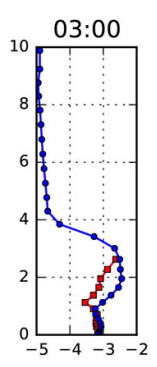

$\log \beta^{*}$
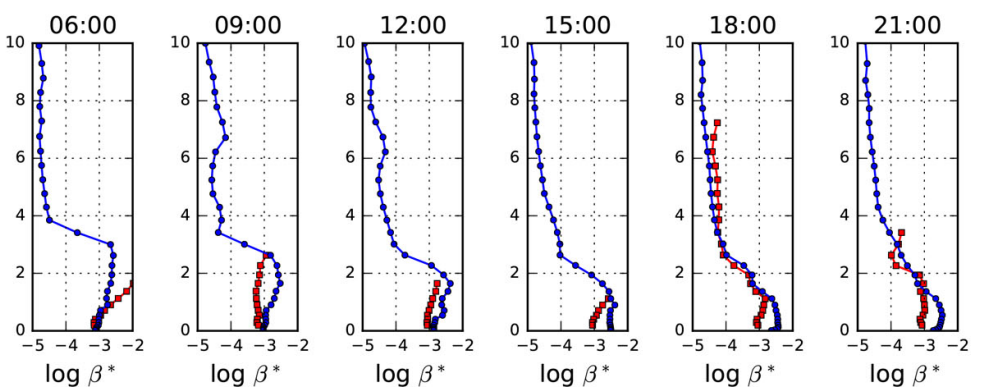

Figure 11. Same as Fig. 10 but for 3 April 2016.
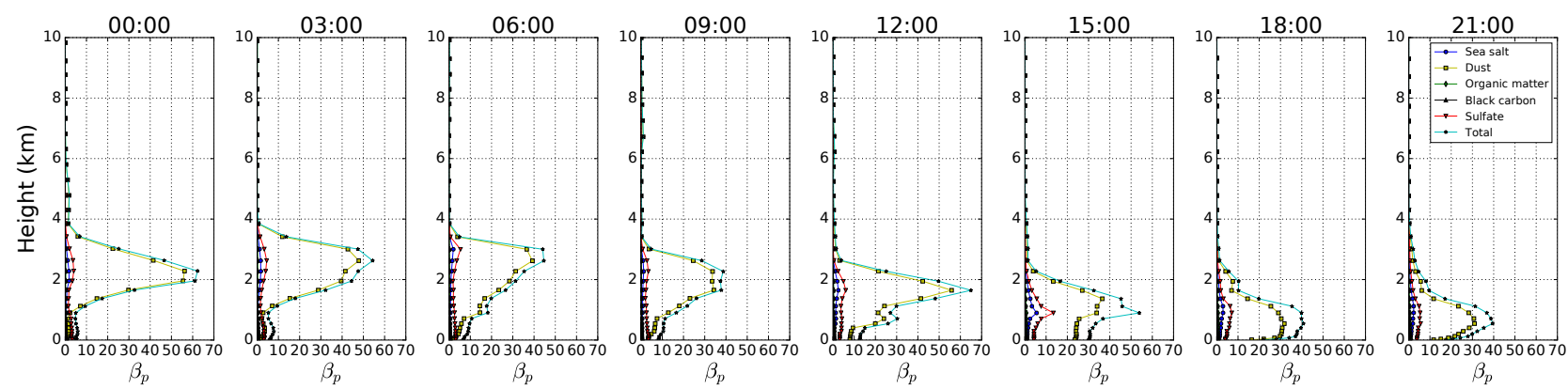

Figure 12. Time series of particle backscatter of the five aerosol types simulated by the model at Elpersbüttel during a dust episode on 3 April 2016.

tion of the vertical extent is hardly possible due to the abovementioned clouds. Again, the upper boundary of the aerosol layer cannot be monitored over the full day, e.g., before 08:00 UTC due to low-level clouds. In contrast to the generally good agreement of $\beta^{*}$ below $1 \mathrm{~km}$, the absolute values differ considerably on 4 April. The discrepancies could be related to the fact that Elpersbüttel was located at the edge of the high aerosol load region at that time (see Fig. 9c). In this case, misallocation of aerosols in a single grid cell would already result in a huge error. In addition, the local aerosol distribution certainly had undergone rapid changes due to several rain showers before 07:00 UTC that might be not resolved by the model.

The overall good agreement between model and observation is confirmed for other sites in Germany. For example, the ceilometer at Soltau, $130 \mathrm{~km}$ southeast of Elpersbüttel, observes the dust layer the first time on 2 April, 17:00 UTC, be- tween 3 and $7 \mathrm{~km}$ - in agreement with the model predictions. This also holds for Pelzerhaken $(120 \mathrm{~km}$ east of Elpersbüttel), where the ceilometer measurements suggest an arrival of the layer shortly before 22:00 UTC, whereas the model results indicate a pronounced dust contribution the first time by 21:00 UTC. Another example is Alfeld, about $250 \mathrm{~km}$ south of Elpersbüttel, where the ceilometer observed the arrival of the dust layer on 2 April, 17:00 UTC. The dust layer was then gradually descending over night and finally merged into the mixing layer on 3 April, 06:00-12:00 UTC. The time-height cross section of the attenuated backscatter of the ceilometer and the corresponding profiles calculated from the model output over Alfeld from 2 to 4 April are shown in Figs. A1, A2 and A3. In central Germany (Offenbach), the arrival time is earlier, approximately at 09:00 UTC according to both model and observations. The upper boundary of the layer is somewhat larger according to the model $(6 \mathrm{~km}$ vs. $4 \mathrm{~km}$ from 
(a) Elpersbüttel 2016-04-04

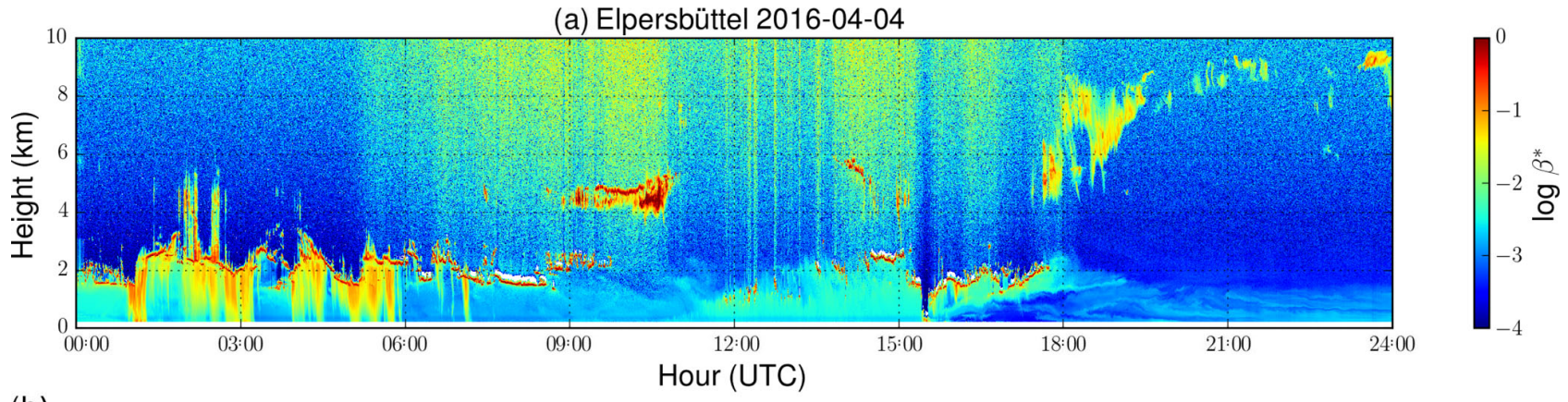

(b)

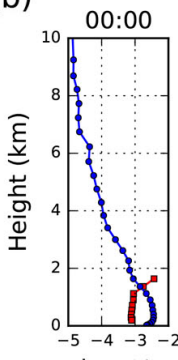

$\log \beta^{*}$

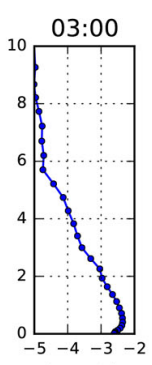

$\log \beta^{*}$
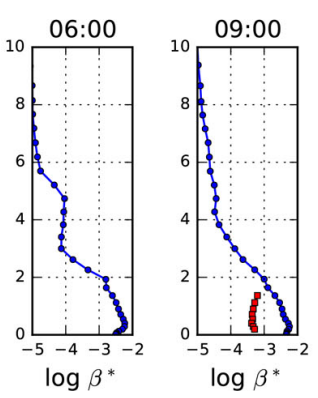

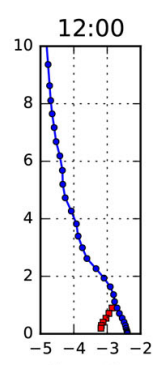

$\log \beta^{*}$

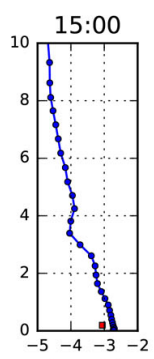

$\log \beta^{*}$

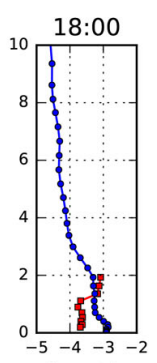

$\log \beta^{*}$

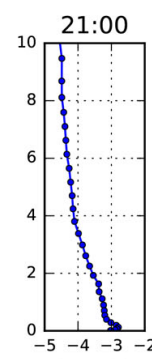

$\log \beta^{*}$

Figure 13. Same as Fig. 10 but for 4 April 2016.

the observations); however, the ceilometer measurements are subject to high solar background limiting their vertical range. For 3 April, the dust event was detected at all stations. In some cases, e.g., Offenbach, the vertical extent of the layer could however not be validated due to low and mid-level clouds.

The case study of the dust episode in April 2016 shows that the model is able to capture such a long-range transport event and compare reasonably well with remote sensing measurements. A network of ceilometers is a powerful tool to validate the arrival, the temporal development and the vertical extent of the dust layer as long as low clouds or precipitation do not block the signals. The agreement of the absolute values of $\beta^{*}$ is however less significant.

\section{Summary and conclusions}

Numerical simulations of spatiotemporal distribution of aerosols are complex due to manifold interactions between chemistry and meteorology, and the heterogeneity of emission sources. Thus, validation of model forecasts is highly desirable. In this paper, we take advantage of a unique infrastructure: the ceilometer network operated by the DWD, providing continuous range-resolved aerosol information at more than 100 stations. We have compared aerosol model simulation of the ECMWF-IFS provided by CAMS with measurements of this ceilometer network. A total of 1 year of data from September 2015 to August 2016 was considered, and we focus on 12 sites within $20 \mathrm{~km}$ of a model grid point. The intercomparison is based on attenuated backscatter $\beta^{*}$, a quantity that can be derived from well calibrated ceilome- ters. As the model includes prognostic equations for the mass mixing ratio of 11 different types of aerosols, $\beta^{*}$ profiles have to be calculated according to the inherent aerosol microphysical properties. Our comparison focuses on the lowest part of the atmosphere, i.e., averages $\overline{\beta_{\mathrm{ns}}^{*}}$ from the mean overlap range of the ceilometers at 0.2 to $1 \mathrm{~km}$ above ground. It shows similar annual averages; however, the standard deviation of the difference is larger than the average in 8 out of 12 sites.

To find reasons for the disagreement, we have examined the role of hygroscopic growth of particles and the role of particle shape. We have calculated $\beta^{*}$ substituting the hygroscopic growth function of sea salt particles based on OPAC by an alternative function reported by Swietlicki et al. (2008). Our calculations show that this change results in a significant reduction of particle backscatter of sea salt. As sea salt is the major contributor to the particle backscatter coefficient, the effect on the modeled attenuated backscatter is on the order of $10 \%$ on average. As a consequence, implementing a realistic hygroscopic growth function is essential for the agreement between ceilometer measurements and model.

The importance of an adequate consideration of the nonspherical shape in the case of mineral dust particles was investigated separately. For this purpose, calculations of optical properties from the Mie theory and the $T$ matrix method assuming spheroids were compared. Application of the latter in the framework of a case study reduces $\beta_{\mathrm{p}}$ of dust by $15-45 \%$, resulting in a better agreement between model and ceilometer measurement. As, on average, the concentration of dust aerosol is very low in Germany, a significant effect on 
the total attenuated backscatter is however confined to dust episodes.

Finally, we have investigated the "agreement" between model and observations in the case of a dust event. In this context, we understand "agreement" as the same time period of the event (appearance, dissolution) and the same vertical extent of the dust layer. The case study shows a quite good general qualitative agreement but also highlights the inherent problems of ceilometer measurements when low clouds are present, and the lack of information on the aerosol type due to the single-wavelength concept.

Intercomparisons as described will certainly benefit from a better model resolution and an extension of the ceilometer network. Then, more cases can be found where the distance between a model grid point and a ceilometer site is a few kilometers only. This would strengthen the conclusions. A recent update of the IFS does indeed provide a resolution of $0.5^{\circ}$, and DWD is continuously extending its ceilometer network. Moreover, attenuated backscatter has been included in the model's output since 26 September 2016, facilitating future intercomparisons.

Our study demonstrated that ceilometer networks could offer several options for the validation of numerical models: not only the vertical profile of $\beta^{*}$ but also the agreement in terms of altitude, extent, temporal development and mean particle backscatter $\beta_{\mathrm{p}}$ of extended/elevated aerosol layers (e.g., volcanic ash) can be considered. In this paper, we have discussed only one dust event for demonstration purposes and found good agreement with respect to the vertical extent of the layer and its temporal development. Whether this finding is valid in general must be investigated in further studies. This effort could benefit from the development of automated algorithms for layer detection. Due to their unprecedented spatial coverage, ceilometer networks may constitute the observational backbone; nevertheless, the combination with the supplementary data set, e.g., from advanced lidar systems and photometers for particle characterization, should be fostered.
Code and data availability. The source code of the ECMWF-IFS model is not available publicly, as it is an operational model running on a routine basis. The ECMWF-IFS model simulation results are available to the meteorological offices of the member states of ECMWF. The raw data of the ceilometer instruments are available on request from the data originator DWD (datenservice@dwd.de). The database of aerosol optical properties used in this study is available on request from the corresponding author (ka.chan@dlr.de). 


\section{Appendix A}

The aerosol microphysical and optical properties at ceilometer and lidar applications relevant wavelengths are listed in Table. The wavelengths corresponding to Nd:YAG lasers used for aerosol remote sensing $(355,532$ and $1064 \mathrm{~nm})$, the widely used Vaisala ceilometers $(910 \mathrm{~nm})$ and the "typical wavelength" for radiative transfer calculations in the shortwave spectral range $(550 \mathrm{~nm})$ are shown.

Figure A1a shows the time-height cross section of the attenuated backscatter of the ceilometer in Alfeld, $\sim 250 \mathrm{~km}$ south of Elpersbüttel, on 2 April 2016, and Fig. A1b shows the corresponding profiles calculated from the model output (blue curve) and retrieved from the ceilometer (red curve). Dust particles are treated as nonspherical particles as defined in Sect. 4.1.2. Note that due to cloud filtering some ceilometer profiles stopped at a relatively low altitude. Similar plots for 3 and 4 April 2016 are shown in Figs. A2 and A3.

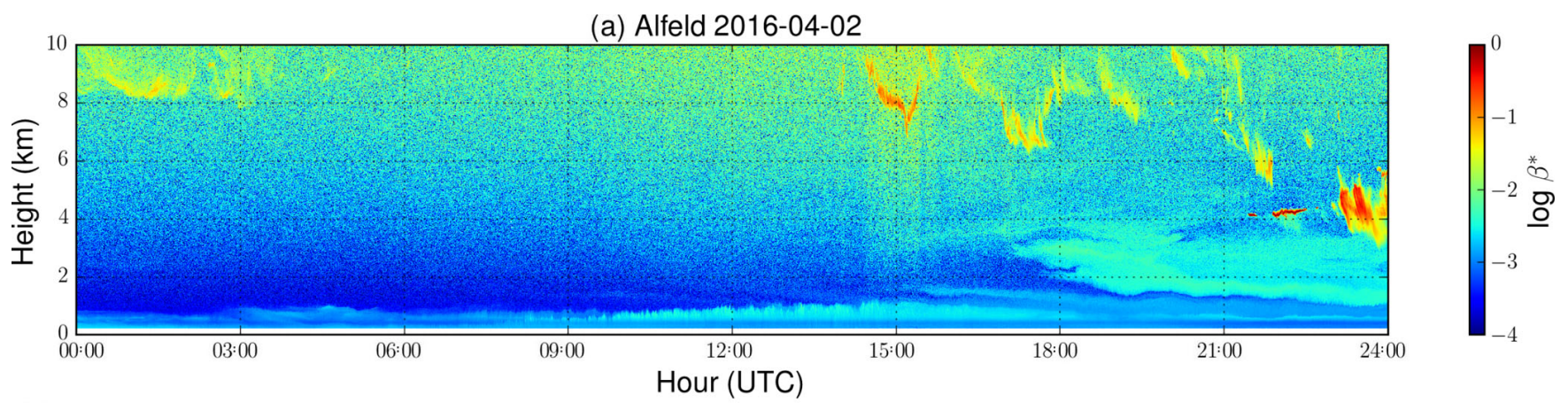

(b)

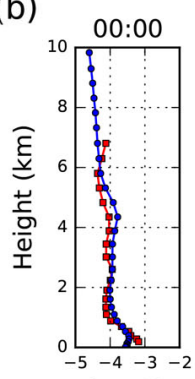

$\log \beta^{*}$

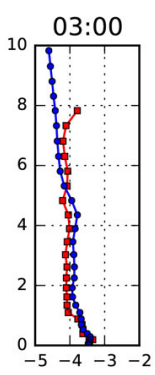

$\log \beta^{*}$

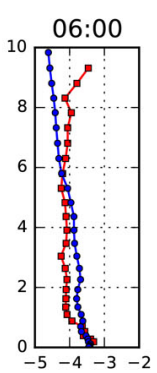

$\log \beta^{*}$

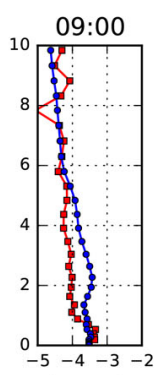

$\log \beta^{*}$

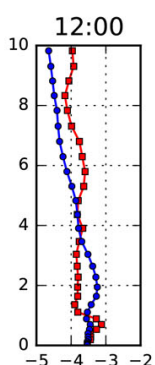

$\log \beta^{*}$

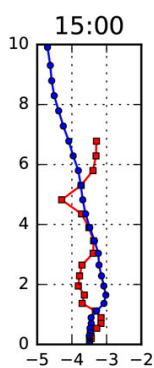

$\log \beta^{*}$

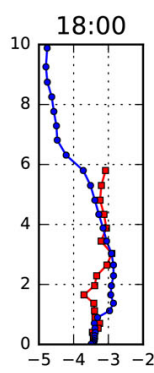

$\log \beta^{*}$

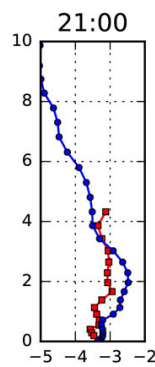

$\log \beta^{*}$

Figure A1. Time series of attenuated backscatter measured by the ceilometer (a) and simulated by the model (b) in Alfeld during a dust episode on 2 April 2016. 


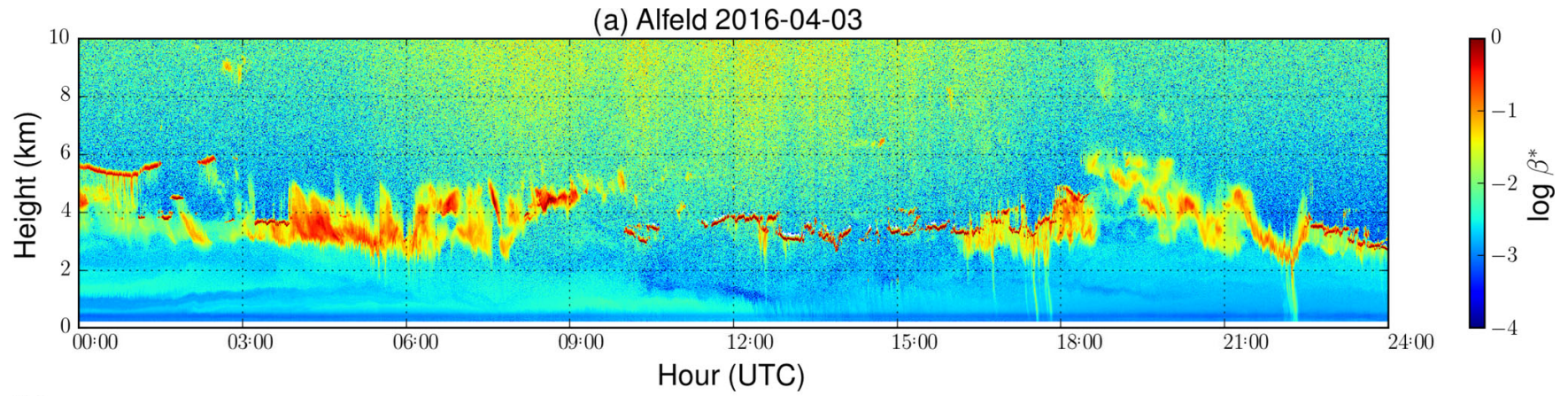

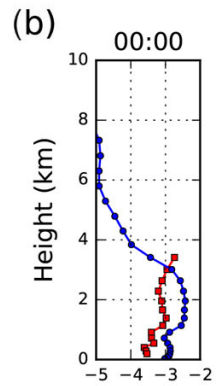

$\log \beta^{*}$

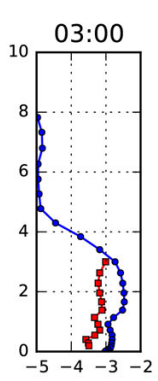

$\log \beta^{*}$
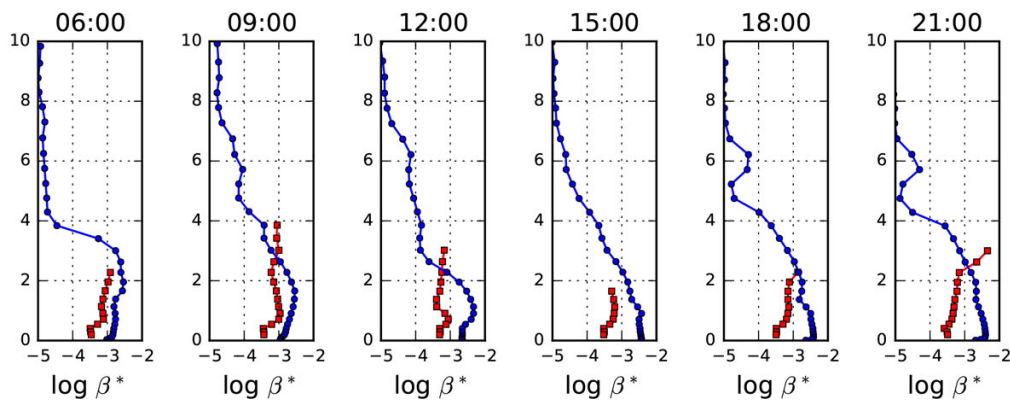

Figure A2. Time series of attenuated backscatter measured by the ceilometer (a) and simulated by the model (b) in Alfeld during a dust episode on 3 April 2016.

(a) Alfeld 2016-04-04
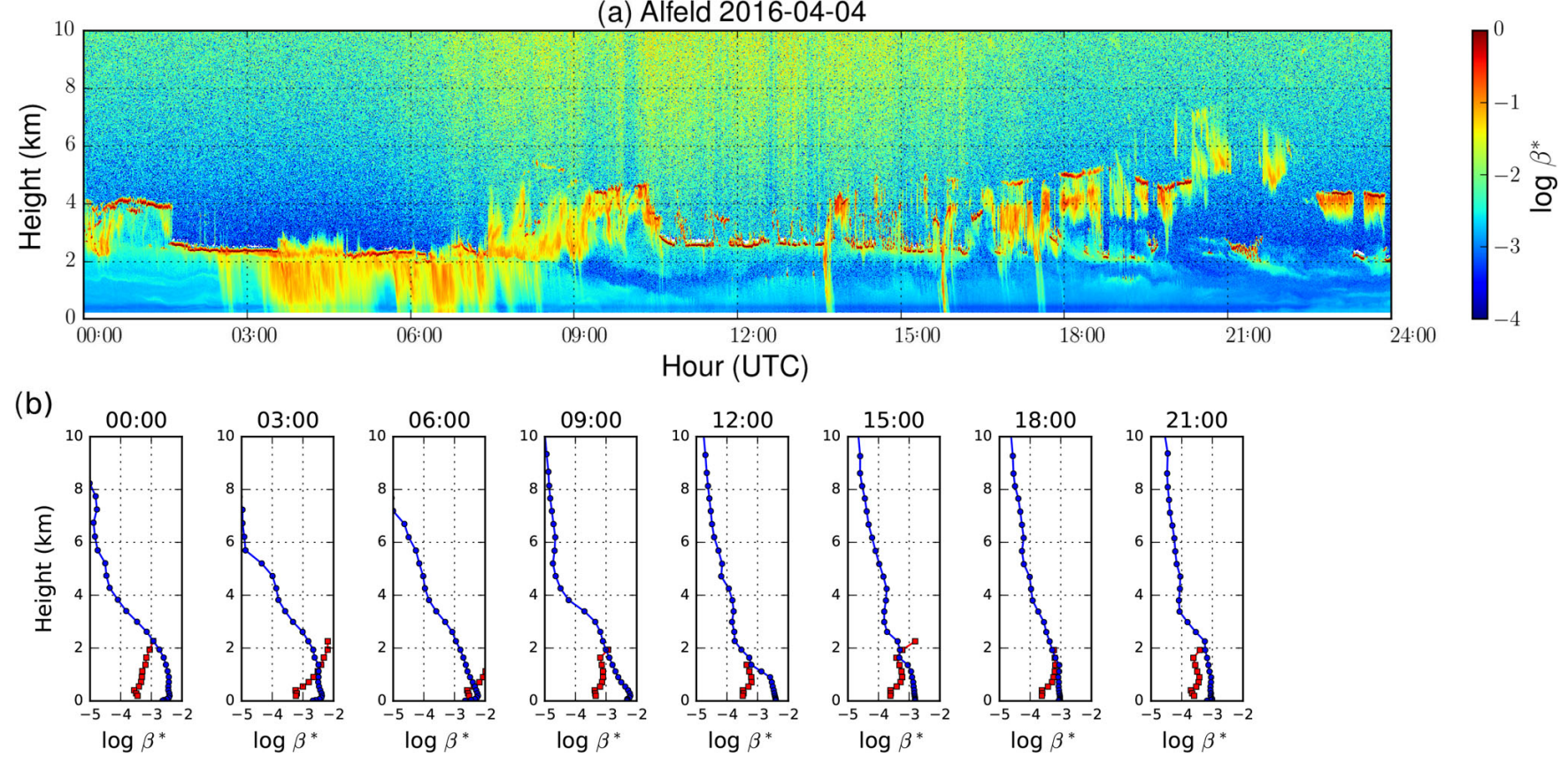

Figure A3. Time series of attenuated backscatter measured by the ceilometer (a) and simulated by the model (b) in Alfeld during a dust episode on 4 April 2016. 


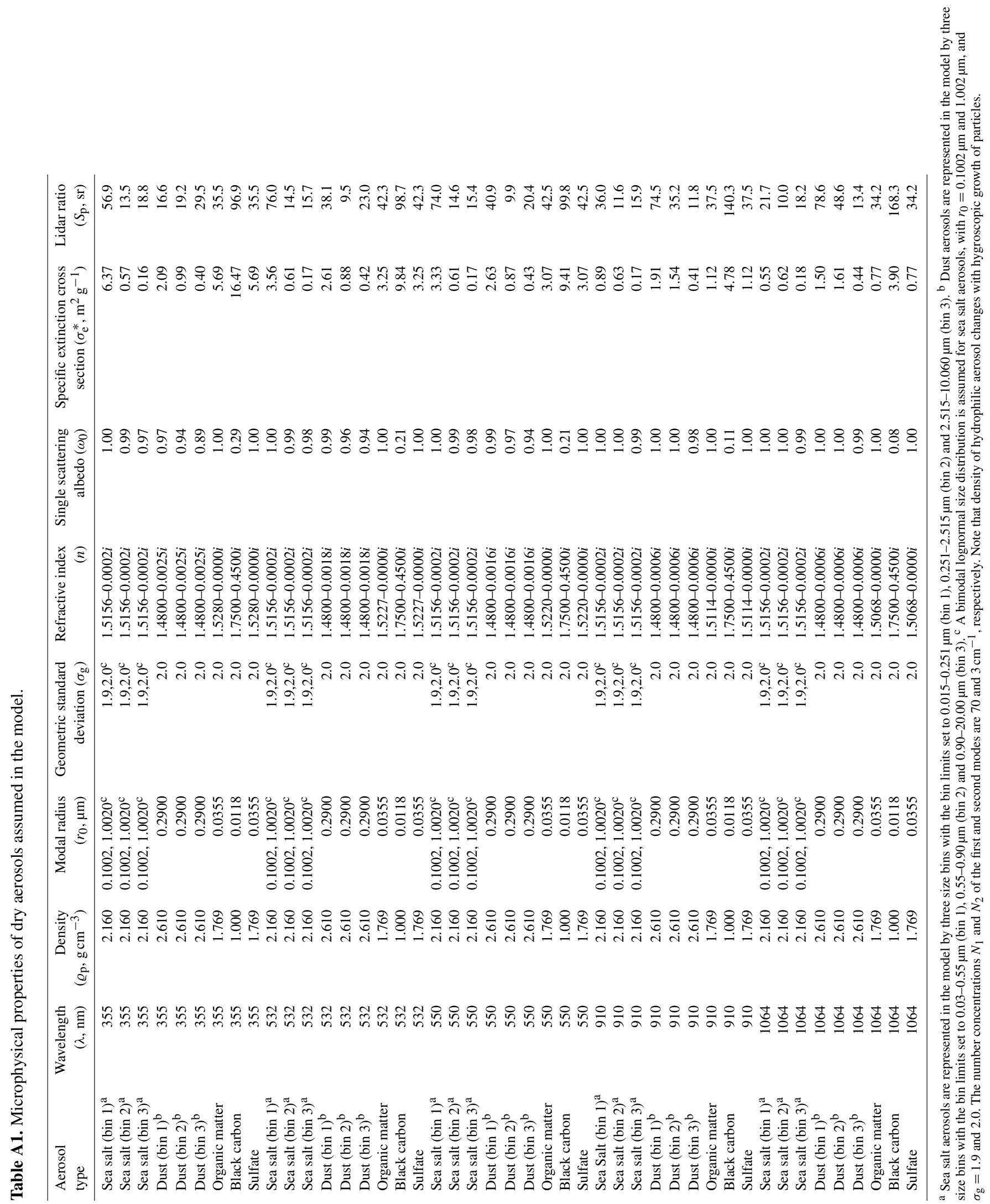


Competing interests. The authors declare that they have no conflict of interest.

Acknowledgements. We thank Maxime Hervo and his colleagues at MeteoSwiss for the provision of the TOPROF/E-PROFILE Rayleigh calibration routine. This work has been partially supported by the European Centre for Medium-Range Weather Forecasts (ECMWF) through its main contractor Royal Netherlands Meteorological Institute (KNMI) and KNMI's subcontractor German Weather Service (DWD) in the context of the Copernicus Atmosphere Monitoring Service (CAMS). The work described in this paper was partially supported by the Marie Curie Initial Training Network of the European Seventh Framework Programme (grant no. 607905) and the European Cooperation in Science and Technology (COST) action "TOPROF" of the European Union's Horizon 2020 program (project no. ES1303). Josef Gasteiger has received funding from the European Research Council (ERC) under the European Union's Horizon 2020 research and innovation program (grant no. 640458, A-LIFE).

The article processing charges for this open-access

publication were covered by a Research

Centre of the Helmholtz Association.

Edited by: Alex B. Guenther

Reviewed by: two anonymous referees

\section{References}

Ansmann, A., Bösenberg, J., Chaikovsky, A., Comerón, A., Eckhardt, S., Eixmann, R., Freudenthaler, V., Ginoux, P., Komguem, L., Linné, H., Márquez, M. n. L., Matthias, V., Mattis, I., Mitev, V., Müller, D., Music, S., Nickovic, S., Pelon, J., Sauvage, L., Sobolewsky, P., Srivastava, M. K., Stohl, A., Torres, O., Vaughan, G., Wandinger, U., and Wiegner, M.: Long-range transport of Saharan dust to northern Europe: The 11-16 October 2001 outbreak observed with EARLINET, J. Geophys. Res.-Atmos., 108, 4783, https://doi.org/10.1029/2003JD003757, 2003.

Baklanov, A., Schlünzen, K., Suppan, P., Baldasano, J., Brunner, D., Aksoyoglu, S., Carmichael, G., Douros, J., Flemming, J., Forkel, R., Galmarini, S., Gauss, M., Grell, G., Hirtl, M., Joffre, S., Jorba, O., Kaas, E., Kaasik, M., Kallos, G., Kong, X., Korsholm, U., Kurganskiy, A., Kushta, J., Lohmann, U., Mahura, A., Manders-Groot, A., Maurizi, A., Moussiopoulos, N., Rao, S. T., Savage, N., Seigneur, C., Sokhi, R. S., Solazzo, E., Solomos, S., Sørensen, B., Tsegas, G., Vignati, E., Vogel, B., and Zhang, Y.: Online coupled regional meteorology chemistry models in Europe: current status and prospects, Atmos. Chem. Phys., 14, 317-398, https://doi.org/10.5194/acp-14-317-2014, 2014.

Balzarini, A., Pirovano, G., Honzak, L., Žabkar, R., Curci, G., Forkel, R., Hirtl, M., José, R. S., Tuccella, P., and Grell, G.: WRF-Chem model sensitivity to chemical mechanisms choice in reconstructing aerosol optical properties, Atmos. Environ., 115, 604-619, https://doi.org/10.1016/j.atmosenv.2014.12.033, 2015.

Barrett, E. W. and Ben-Dov, O.: Application of the Lidar to Air Pollution Measurements, J. Appl. Me- teorol., $\quad 6, \quad 500-515, \quad$ https://doi.org/10.1175/15200450(1967)006<0500:AOTLTA>2.0.CO;2, 1967.

Bechtold, P., Kohler, M., Jung, T., Doblas-Reyes, F., Leutbecher, M., Rodwell, M. J., Vitart, F., and Balsamo, G.: Advances in simulating atmospheric variability with the ECMWF model: From synoptic to decadal time-scales, Q. J. Roy. Meteor. Soc., 134, 1337-1351, https://doi.org/10.1002/qj.289, 2008.

Benedetti, A., Morcrette, J.-J., Boucher, O., Dethof, A., Engelen, R. J., Fisher, M., Flentje, H., Huneeus, N., Jones, L., Kaiser, J. W., Kinne, S., Mangold, A., Razinger, M., Simmons, A. J., and Suttie, M.: Aerosol analysis and forecast in the European Centre for Medium-Range Weather Forecasts Integrated Forecast System: 2. Data assimilation, J. Geophys. Res.-Atmos., 114, d13205, https://doi.org/10.1029/2008JD011115, 2009.

Beuck, H., Quass, U., Klemm, O., and Kuhlbusch, T.: Assessment of sea salt and mineral dust contributions to $\mathrm{PM}_{10}$ in NW Germany using tracer models and positive matrix factorization, Atmos. Environ., 45, 5813-5821, https://doi.org/10.1016/j.atmosenv.2011.07.010, 2011.

Binietoglou, I., Basart, S., Alados-Arboledas, L., Amiridis, V., Argyrouli, A., Baars, H., Baldasano, J. M., Balis, D., Belegante, L., Bravo-Aranda, J. A., Burlizzi, P., Carrasco, V., Chaikovsky, A., Comerón, A., D’Amico, G., Filioglou, M., Granados-Muñoz, M. J., Guerrero-Rascado, J. L., Ilic, L., Kokkalis, P., Maurizi, A., Mona, L., Monti, F., Muñoz-Porcar, C., Nicolae, D., Papayannis, A., Pappalardo, G., Pejanovic, G., Pereira, S. N., Perrone, M. R., Pietruczuk, A., Posyniak, M., Rocadenbosch, F., Rodríguez-Gómez, A., Sicard, M., Siomos, N., Szkop, A., Terradellas, E., Tsekeri, A., Vukovic, A., Wandinger, U., and Wagner, J.: A methodology for investigating dust model performance using synergistic EARLINET/AERONET dust concentration retrievals, Atmos. Meas. Tech., 8, 3577-3600, https://doi.org/10.5194/amt-8-3577-2015, 2015.

Boucher, O. and Anderson, T. L.: General circulation model assessment of the sensitivity of direct climate forcing by anthropogenic sulfate aerosols to aerosol size and chemistry, J. Geophys. Res.Atmos., 100, 26117-26134, https://doi.org/10.1029/95JD02531, 1995.

Boucher, O., Pham, M., and Venkataraman, C.: Simulation of the atmospheric sulfur cycle in the LMD GCM: Model description, model evaluation, and global and European budgets, Tech. rep., Note, 2002.

Buizza, R., Milleer, M., and Palmer, T. N.: Stochastic representation of model uncertainties in the ECMWF ensemble prediction system, Q. J. Roy. Meteor. Soc., 125, 2887-2908, https://doi.org/10.1002/qj.49712556006, 1999.

Cazorla, A., Casquero-Vera, J. A., Román, R., Guerrero-Rascado, J. L., Toledano, C., Cachorro, V. E., Orza, J. A. G., Cancillo, M. L., Serrano, A., Titos, G., Pandolfi, M., Alastuey, A., Hanrieder, N., and Alados-Arboledas, L.: Near-real-time processing of a ceilometer network assisted with sun-photometer data: monitoring a dust outbreak over the Iberian Peninsula, Atmos. Chem. Phys., 17, 11861-11876, https://doi.org/10.5194/acp-17-118612017, 2017.

Chaikovsky, A., Dubovik, O., Holben, B., Bril, A., Goloub, P., Tanré, D., Pappalardo, G., Wandinger, U., Chaikovskaya, L., Denisov, S., Grudo, J., Lopatin, A., Karol, Y., Lapyonok, T., Amiridis, V., Ansmann, A., Apituley, A., Allados-Arboledas, L., Binietoglou, I., Boselli, A., D’Amico, G., Freudenthaler, V., 
Giles, D., Granados-Muñoz, M. J., Kokkalis, P., Nicolae, D., Oshchepkov, S., Papayannis, A., Perrone, M. R., Pietruczuk, A., Rocadenbosch, F., Sicard, M., Slutsker, I., Talianu, C., De Tomasi, F., Tsekeri, A., Wagner, J., and Wang, X.: Lidar-Radiometer Inversion Code (LIRIC) for the retrieval of vertical aerosol properties from combined lidar/radiometer data: development and distribution in EARLINET, Atmos. Meas. Tech., 9, 1181-1205, https://doi.org/10.5194/amt-9-1181-2016, 2016.

Chan, K. L.: Biomass burning sources and their contributions to the local air quality in Hong Kong, Sci. Total Environ., 596-597, 212-221, https://doi.org/10.1016/j.scitotenv.2017.04.091, 2017.

Chan, K. L. and Chan, K. L.: Aerosol optical depths and their contributing sources in Taiwan, Atmos. Environ., 148, 364-375, https://doi.org/10.1016/j.atmosenv.2016.11.011, 2017.

Chin, M., Ginoux, P., Kinne, S., Torres, O., Holben, B. N., Duncan, B. N., Martin, R. V., Logan, J. A., Higurashi, A., and Nakajima, T.: Tropospheric Aerosol Optical Thickness from the GOCART Model and Comparisons with Satellite and Sun Photometer Measurements, J. Atmos. Sci., 59, 461-483, https://doi.org/10.1175/15200469(2002)059<0461:TAOTFT>2.0.CO;2, 2002.

Cuevas, E., Camino, C., Benedetti, A., Basart, S., Terradellas, E., Baldasano, J. M., Morcrette, J. J., Marticorena, B., Goloub, P., Mortier, A., Berjón, A., Hernández, Y., Gil-Ojeda, M., and Schulz, M.: The MACC-II 2007-2008 reanalysis: atmospheric dust evaluation and characterization over northern Africa and the Middle East, Atmos. Chem. Phys., 15, 3991-4024, https://doi.org/10.5194/acp-15-3991-2015, 2015.

Curci, G., Hogrefe, C., Bianconi, R., Im, U., Balzarini, A., Baró, R., Brunner, D., Forkel, R., Giordano, L., Hirtl, M., Honzak, L., Jiménez-Guerrero, P., Knote, C., Langer, M., Makar, P., Pirovano, G., Pérez, J., José, R. S., Syrakov, D., Tuccella, P., Werhahn, J., Wolke, R., Žabkar, R., Zhang, J., and Galmarini, S.: Uncertainties of simulated aerosol optical properties induced by assumptions on aerosol physical and chemical properties: An AQMEII-2 perspective, Atmos. Environ., 115, 541-552, https://doi.org/10.1016/j.atmosenv.2014.09.009, 2015.

Dentener, F., Kinne, S., Bond, T., Boucher, O., Cofala, J., Generoso, S., Ginoux, P., Gong, S., Hoelzemann, J. J., Ito, A., Marelli, L., Penner, J. E., Putaud, J.-P., Textor, C., Schulz, M., van der Werf, G. R., and Wilson, J.: Emissions of primary aerosol and precursor gases in the years 2000 and 1750 prescribed data-sets for AeroCom, Atmos. Chem. Phys., 6, 43214344, https://doi.org/10.5194/acp-6-4321-2006, 2006.

Drusch, M., Scipal, K., de Rosnay, P., Balsamo, G., Andersson, E., Bougeault, P., and Viterbo, P.: Towards a Kalman Filter based soil moisture analysis system for the operational ECMWF Integrated Forecast System, Geophys. Res. Lett., 36, 110401, https://doi.org/10.1029/2009GL037716, 2009.

Dubovik, O., Holben, B., Eck, T. F., Smirnov, A., Kaufman, Y. J., King, M. D., Tanré, D., and Slutsker, I.: Variability of absorption and optical properties of key aerosol types observed in worldwide locations, J. Atmos. Sci., 59, 590-608, 2002.

Dutra, E., Diamantakis, M., Tsonevsky, I., Zsoter, E., Wetterhall, F., Stockdale, T., Richardson, D., and Pappenberger, F.: The extreme forecast index at the seasonal scale, Atmos. Sci. Lett., 14, 256262, https://doi.org/10.1002/as12.448, 2013.

EDGAR: Emission Database for Global Atmospheric Research (EDGAR), release EDGARv4.2 FT2010, Tech. rep., European
Commission, Joint Research Centre (JRC)/Netherlands Environmental Assessment Agency (PBL), 2013.

Emeis, S., Forkel, R., Junkermann, W., Schäfer, K., Flentje, H., Gilge, S., Fricke, W., Wiegner, M., Freudenthaler, V., Groß, S., Ries, L., Meinhardt, F., Birmili, W., Münkel, C., Obleitner, F., and Suppan, P.: Measurement and simulation of the 16/17 April 2010 Eyjafjallajökull volcanic ash layer dispersion in the northern Alpine region, Atmos. Chem. Phys., 11, 2689-2701, https://doi.org/10.5194/acp-11-2689-2011, 2011.

Engelstaedter, S. and Washington, R.: Temporal controls on global dust emissions: The role of surface gustiness, Geophys. Res Lett., 34, 115805, https://doi.org/10.1029/2007GL029971, 2007.

Fast, J. D., Gustafson, W. I., Easter, R. C., Zaveri, R. A., Barnard, J. C., Chapman, E. G., Grell, G. A., and Peckham, S. E.: Evolution of ozone, particulates, and aerosol direct radiative forcing in the vicinity of Houston using a fully coupled meteorology-chemistry-aerosol model, J. Geophys. Res.-Atmos., 111, D21305, https://doi.org/10.1029/2005JD006721, 2006.

Fernald, F. G.: Analysis of atmospheric lidar observations: some comments, Appl. Optics, 23, 652-653, https://doi.org/10.1364/AO.23.000652, 1984.

Flentje, H., Claude, H., Elste, T., Gilge, S., Köhler, U., PlassDülmer, C., Steinbrecht, W., Thomas, W., Werner, A., and Fricke, W.: The Eyjafjallajökull eruption in April 2010 - detection of volcanic plume using in-situ measurements, ozone sondes and lidar-ceilometer profiles, Atmos. Chem. Phys., 10, 10085-10092, https://doi.org/10.5194/acp-10-10085-2010, 2010.

Flentje, H., Briel, B., Beck, C., Coen, M. C., Fricke, M., Cyrys, J., Gu, J., Pitz, M., and Thomas, W.: Identification and monitoring of Saharan dust: An inventory representative for south Germany since 1997, Atmos. Environ., 109, 87-96, https://doi.org/10.1016/j.atmosenv.2015.02.023, 2015.

Forkel, R., Balzarini, A., Baró, R., Bianconi, R., Curci, G., JiménezGuerrero, P., Hirtl, M., Honzak, L., Lorenz, C., Im, U., Pérez, J. L., Pirovano, G., José, R. S., Tuccella, P., Werhahn, J., and Žabkar, R.: Analysis of the WRF-Chem contributions to AQMEII phase 2 with respect to aerosol radiative feedbacks on meteorology and pollutant distributions, Atmos. Environ., 115, 630-645, https://doi.org/10.1016/j.atmosenv.2014.10.056, 2015.

Geisinger, A., Behrendt, A., Wulfmeyer, V., Strohbach, J., Förstner, J., and Potthast, R.: Development and application of a backscatter lidar forward operator for quantitative validation of aerosol dispersion models and future data assimilation, Atmos. Meas. Tech., 10, 4705-4726, https://doi.org/10.5194/amt10-4705-2017, 2017.

Grell, G. A., Peckham, S. E., Schmitz, R., McKeen, S. A., Frost, G., Skamarock, W. C., and Eder, B.: Fully coupled "online" chemistry within the WRF model, Atmos. Environ., 39, 6957-6975, https://doi.org/10.1016/j.atmosenv.2005.04.027, 2005.

Groß, S., Freudenthaler, V., Schepanski, K., Toledano, C., Schäfler, A., Ansmann, A., and Weinzierl, B.: Optical properties of long-range transported Saharan dust over Barbados as measured by dual-wavelength depolarization Raman lidar measurements, Atmos. Chem. Phys., 15, 11067-11080, https://doi.org/10.5194/acp-15-11067-2015, 2015.

Guelle, W., Balkanski, Y. J., Schulz, M., Marticorena, B., Bergametti, G., Moulin, C., Arimoto, R., and Perry, K. D. Modeling the atmospheric distribution of mineral aerosol: Comparison with ground measurements and satellite ob- 
servations for yearly and synoptic timescales over the North Atlantic, J. Geophys. Res.-Atmos., 105, 1997-2012, https://doi.org/10.1029/1999JD901084, 2000.

Hess, M., Koepke, P., and Schult, I.: Optical properties of aerosols and clouds: The software package OPAC, B. Am. Meteorol. Soc., 79, 8-844, 1998.

Im, U., Bianconi, R., Solazzo, E., Kioutsioukis, I., Badia, A., Balzarini, A., Baró, R., Bellasio, R., Brunner, D., Chemel, C., Curci, G., van der Gon, H. D., Flemming, J., Forkel, R., Giordano, L., Jiménez-Guerrero, P., Hirtl, M., Hodzic, A., Honzak, L., Jorba, O., Knote, C., Makar, P. A., Manders-Groot, A., Neal, L., Pérez, J. L., Pirovano, G., Pouliot, G., Jose, R. S., Savage, N., Schroder, W., Sokhi, R. S., Syrakov, D., Torian, A., Tuccella, P., Wang, K., Werhahn, J., Wolke, R., Zabkar, R., Zhang, Y., Zhang, J., Hogrefe, C., and Galmarini, S.: Evaluation of operational online-coupled regional air quality models over Europe and North America in the context of AQMEII phase 2. Part II: Particulate matter, Atmos. Environ., 115, 421-441, https://doi.org/10.1016/j.atmosenv.2014.08.072, 2015.

IPCC: IPCC, 2012: Managing the Risks of Extreme Events and Disasters to Advance Climate Change Adaptation. A Special Report of Working Groups I and II of the Intergovernmental Panel on Climate Change, Cambridge University Press, Cambridge, UK, and New York, NY, USA, 2012.

Jones, A., Roberts, D. L., Woodage, M. J., and Johnson, C. E.: Indirect sulphate aerosol forcing in a climate model with an interactive sulphur cycle, J. Geophys. Res.-Atmos., 106, 20293-20310, https://doi.org/10.1029/2000JD000089, 2001.

Kalnay, E., Kanamitsu, M., Kistler, R., Collins, W., Deaven, D., Gandin, L., Iredell, M., Saha, S., White, G., Woollen, J., Zhu, Y., Chelliah, M., Ebisuzaki, W., Higgins, W., Janowiak, J., Mo, K. C., Ropelewski, C., Wang, J., Leetmaa, A., Reynolds, R., Jenne, R., and Joseph, D.: The NCEP/NCAR 40-year reanalysis project, B. Am. Meteorol. Soc., 77, 437-471, 1996.

Kandler, K., Schütz, L., Deutscher, C., Ebert, M., Hofmann, H., Jäckel, S., Jaenicke, R., Knippertz, P., Lieke, K., Massling, A., Petzold, A., Schladitz, A., Weinzierl, B., Wiedensohler, A., Zorn, S., and Weinbruch, S.: Size distribution, mass concentration, chemical and mineralogical composition and derived optical parameters of the boundary layer aerosol at Tinfou, Morocco, during SAMUM 2006, Tellus B, 61, 32-50, https://doi.org/10.1111/j.1600-0889.2008.00385.x, 2009.

Kazil, J., Stier, P., Zhang, K., Quaas, J., Kinne, S., O’Donnell, D., Rast, S., Esch, M., Ferrachat, S., Lohmann, U., and Feichter, J.: Aerosol nucleation and its role for clouds and Earth's radiative forcing in the aerosol-climate model ECHAM5-HAM, Atmos. Chem. Phys., 10, 10733-10752, https://doi.org/10.5194/acp-1010733-2010, 2010.

Klett, J. D.: Stable analytical inversion solution for processing lidar returns, Appl. Optics, 20, 211-220, https://doi.org/10.1364/AO.20.000211, 1981.

Köpke, P., Hess, M., Schult, I., and Shettle, E.: Global aerosol data set, Max-Planck-Institut für Meteorologie Hamburg, Germany, 1997.

Lohmann, U., Stier, P., Hoose, C., Ferrachat, S., Kloster, S., Roeckner, E., and Zhang, J.: Cloud microphysics and aerosol indirect effects in the global climate model ECHAM5-HAM, Atmos. Chem. Phys., 7, 3425-3446, https://doi.org/10.5194/acp-7-34252007, 2007.
Mishchenko, M. I. and Travis, L. D.: Capabilities and limitations of a current FORTRAN implementation of the T-matrix method for randomly oriented, rotationally symmetric scatterers, J. Quant. Spectrosc. Ra., 60, 309-324, https://doi.org/10.1016/S00224073(98)00008-9, 1998.

Mishchenko, M. I., Dlugach, J. M., Yanovitskij, E. G., and Zakharova, N. T.: Bidirectional reflectance of flat, optically thick particulate layers: an efficient radiative transfer solution and applications to snow and soil surfaces, J. Quant. Spectrosc. Ra., 63, 409-432, https://doi.org/10.1016/S0022-4073(99)00028-X, 1999.

Mona, L., Papagiannopoulos, N., Basart, S., Baldasano, J., Binietoglou, I., Cornacchia, C., and Pappalardo, G.: EARLINET dust observations vs. BSC-DREAM8b modeled profiles: 12year-long systematic comparison at Potenza, Italy, Atmos. Chem. Phys., 14, 8781-8793, https://doi.org/10.5194/acp-148781-2014, 2014.

Morcrette, J.-J., Beljaars, A., Benedetti, A., Jones, L., and Boucher, O.: Sea-salt and dust aerosols in the ECMWF IFS model, Geophys. Res. Lett., 35, 124813, https://doi.org/10.1029/2008GL036041, 2008.

Morcrette, J.-J., Boucher, O., Jones, L., Salmond, D., Bechtold, P., Beljaars, A., Benedetti, A., Bonet, A., Kaiser, J. W., Razinger, M., Schulz, M., Serrar, S., Simmons, A. J., Sofiev, M., Suttie, M., Tompkins, A. M., and Untch, A.: Aerosol analysis and forecast in the European Centre for Medium-Range Weather Forecasts Integrated Forecast System: Forward modeling, J. Geophys. Res.Atmos., 114, d06206, https://doi.org/10.1029/2008JD011235, 2009.

Müller, D., Heinold, B., Tesche, M., Tegen, I., Althausen, D., Arboledas, L. A., Amiridis, V., Amodeo, A., Ansmann, A., Balis, D., Comeron, A., D'amico, G., Gerasopoulos, E., GuerreroRascado, J. L., Freudenthaler, V., Giannakaki, E., Heese, B., Iarlori, M., Knippertz, P., Mamouri, R. E., Mona, L., Papayannis, A., Pappalardo, G., Perrone, R.-M., Pisani, G., Rizi, V., Sicard, M., Spinelli, N., Tafuro, A., and Wiegner, M.: EARLINET observations of the 14-22 May long-range dust transport event during SAMUM 2006: validation of results from dust transport modelling, Tellus B, 61, 325-339, https://doi.org/10.1111/j.16000889.2008.00400.x, 2009.

O’Dowd, C. D., Lowe, J. A., Smith, M. H., Davison, B., Hewitt, C. N., and Harrison, R. M.: Biogenic sulphur emissions and inferred non-sea-salt-sulphate cloud condensation nuclei in and around Antarctica, J. Geophys. Res.-Atmos., 102, 12839-12854, https://doi.org/10.1029/96JD02749, 1997.

Rabier, F., Jarvinen, H., Klinker, E., Mahfouf, J.-F., and Simmons, A.: The ECMWF operational implementation of fourdimensional variational assimilation. I: Experimental results with simplified physics, Q. J. Roy. Meteor. Soc., 126, 1143-1170, https://doi.org/10.1002/qj.49712656415, 2000.

Rao, S. T., Galmarini, S., and Puckett, K.: Air Quality Model Evaluation International Initiative (AQMEII): Advancing the State of the Science in Regional Photochemical Modeling and Its Applications, B. Am. Meteorol. Soc., 92, 23-30, https://doi.org/10.1175/2010BAMS3069.1, 2011.

Reddy, M. S., Boucher, O., Bellouin, N., Schulz, M., Balkanski, Y., Dufresne, J.-L., and Pham, M.: Estimates of global multicomponent aerosol optical depth and direct radiative perturbation in the Laboratoire de Meteorologie Dynamique gen- 
eral circulation model, J. Geophys. Res.-Atmos., 110, d10S16, https://doi.org/10.1029/2004JD004757, 2005.

Shettle, E. P. and Fenn, R. W.: Models for the aerosols of the lower atmosphere and the effects of humidity variations on their optical properties, Tech. Rep. Environmental research papers No. 675, NTIS, ADA 085951, AFGL-TR-79-0214, Air Force Geophysics Lab Hanscom Afb Ma, 1979.

Siomos, N., Balis, D. S., Poupkou, A., Liora, N., Dimopoulos, S., Melas, D., Giannakaki, E., Filioglou, M., Basart, S., and Chaikovsky, A.: Investigating the quality of modeled aerosol profiles based on combined lidar and sunphotometer data, Atmos. Chem. Phys., 17, 7003-7023, https://doi.org/10.5194/acp17-7003-2017, 2017.

Solazzo, E., Bianconi, R., Pirovano, G., Matthias, V., Vautard, R., Moran, M. D., Appel, K. W., Bessagnet, B., Brandt, J., Christensen, J. H., Chemel, C., Coll, I., Ferreira, J., Forkel, R., Francis, X. V., Grell, G., Grossi, P., Hansen, A. B., Miranda, A. I., Nopmongcol, U., Prank, M., Sartelet, K. N., Schaap, M., Silver, J. D., Sokhi, R. S., Vira, J., Werhahn, J., Wolke, R., Yarwood, G., Zhang, J., Rao, S. T., and Galmarini, S.: Operational model evaluation for particulate matter in Europe and North America in the context of AQMEII, Atmos. Environ., 53, 75-92, https://doi.org/10.1016/j.atmosenv.2012.02.045, 2012.

Stier, P., Feichter, J., Kinne, S., Kloster, S., Vignati, E., Wilson, J., Ganzeveld, L., Tegen, I., Werner, M., Balkanski, Y., Schulz, M., Boucher, O., Minikin, A., and Petzold, A.: The aerosol-climate model ECHAM5-HAM, Atmos. Chem. Phys., 5, 1125-1156, https://doi.org/10.5194/acp-5-1125-2005, 2005.

Stuut, J.-B., Smalley, I., and O'Hara-Dhand, K.: Aeolian dust in Europe: African sources and European deposits, Quaternary Int., 198, 234-245, https://doi.org/10.1016/j.quaint.2008.10.007, 2009.

Swietlicki, E., Hansson, H.-C., Hämeri, K., Svenningsson, B., Massling, A., Mcfiggans, G., Mcmurry, P. H., PetäJä, T., Tunved, P., Gysel, M., Topping, D., Weingartner, E., Baltensperger, U., Rissler, J., Wiedensohler, A., and Kulmala, M.: Hygroscopic properties of submicrometer atmospheric aerosol particles measured with H-TDMA instruments in various environments - a review, Tellus B, 60, 432-469, https://doi.org/10.1111/j.16000889.2008.00350.x, 2008.

van der Gon, H. D., Beevers, S., D’Allura, A., Finardi, S., Honoré, C., Kuenen, J., Perrussel, O., Radice, P., Theloke, J., Uzbasich, M., and Visschedijk, A.: Discrepancies Between Top-Down and Bottom-Up Emission Inventories of Megacities: The Causes and Relevance for Modeling Concentrations and Exposure, in: Air Pollution Modeling and its Application XXI, edited by: Steyn, D. G. and Trini Castelli, S., Springer Netherlands, Dordrecht, 199-204, 2012.

van der Werf, G. R., Randerson, J. T., Giglio, L., Collatz, G. J., Mu, M., Kasibhatla, P. S., Morton, D. C., DeFries, R. S., Jin, Y., and van Leeuwen, T. T.: Global fire emissions and the contribution of deforestation, savanna, forest, agricultural, and peat fires (1997-2009), Atmos. Chem. Phys., 10, 11707-11735, https://doi.org/10.5194/acp-10-11707-2010, 2010.
Wang, M., Ghan, S., Ovchinnikov, M., Liu, X., Easter, R., Kassianov, E., Qian, Y., and Morrison, H.: Aerosol indirect effects in a multi-scale aerosol-climate model PNNL-MMF, Atmos. Chem. Phys., 11, 5431-5455, https://doi.org/10.5194/acp11-5431-2011, 2011.

Wang, Y., Sartelet, K. N., Bocquet, M., Chazette, P., Sicard, M., D’Amico, G., Léon, J. F., Alados-Arboledas, L., Amodeo, A., Augustin, P., Bach, J., Belegante, L., Binietoglou, I., Bush, X., Comerón, A., Delbarre, H., García-Vízcaino, D., GuerreroRascado, J. L., Hervo, M., Iarlori, M., Kokkalis, P., Lange, D., Molero, F., Montoux, N., Muñoz, A., Muñoz, C., Nicolae, D., Papayannis, A., Pappalardo, G., Preissler, J., Rizi, V., Rocadenbosch, F., Sellegri, K., Wagner, F., and Dulac, F.: Assimilation of lidar signals: application to aerosol forecasting in the western Mediterranean basin, Atmos. Chem. Phys., 14, 12031-12053, https://doi.org/10.5194/acp-14-12031-2014, 2014.

Waterman, P. C.: Symmetry, Unitarity, and Geometry in Electromagnetic Scattering, Phys. Rev. D, 3, 825-839, https://doi.org/10.1103/PhysRevD.3.825, 1971.

Wiegner, M. and Gasteiger, J.: Correction of water vapor absorption for aerosol remote sensing with ceilometers, Atmos. Meas. Tech., 8, 3971-3984, https://doi.org/10.5194/amt-8-3971-2015, 2015.

Wiegner, M. and Geiß, A.: Aerosol profiling with the Jenoptik ceilometer CHM15kx, Atmos. Meas. Tech., 5, 1953-1964, https://doi.org/10.5194/amt-5-1953-2012, 2012.

Wiegner, M., Groß, S., Freudenthaler, V., Schnell, F., and Gasteiger, J.: The May/June 2008 Saharan dust event over Munich: Intensive aerosol parameters from lidar measurements, J. Geophys. Res.-Atmos., 116, D23213, https://doi.org/10.1029/2011JD016619, 2011.

Wiegner, M., Madonna, F., Binietoglou, I., Forkel, R., Gasteiger, J., Geiß, A., Pappalardo, G., Schäfer, K., and Thomas, W.: What is the benefit of ceilometers for aerosol remote sensing? An answer from EARLINET, Atmos. Meas. Tech., 7, 1979-1997, https://doi.org/10.5194/amt-7-1979-2014, 2014.

Zhang, K., O’Donnell, D., Kazil, J., Stier, P., Kinne, S., Lohmann, U., Ferrachat, S., Croft, B., Quaas, J., Wan, H., Rast, S., and Feichter, J.: The global aerosol-climate model ECHAM-HAM, version 2: sensitivity to improvements in process representations, Atmos. Chem. Phys., 12, 8911-8949, https://doi.org/10.5194/acp-12-8911-2012, 2012.

Zieger, P., Fierz-Schmidhauser, R., Weingartner, E., and Baltensperger, U.: Effects of relative humidity on aerosol light scattering: results from different European sites, Atmos. Chem. Phys., 13, 10609-10631, https://doi.org/10.5194/acp-13-106092013, 2013. 